\title{
Non-Surgical Treatment of Knee Osteoarthritis: Multidisciplinary Italian Consensus on Best Practice
}

\author{
Lorenzo Pradelli iD \\ Tiziana Sinigaglia' \\ Alberto Migliore iD ${ }^{2}$ \\ Giovanni Antonio Checchia ${ }^{3}{ }^{3}$ \\ Francesco Franceschi ${ }^{4}$ \\ Bruno Frediani $^{5}$ \\ Florenzo lannone (D) $^{6}$ \\ Emilio Romanini ${ }^{7}{ }^{7}$ \\ 'AdRes HE\&OR, Torino, Italy; ${ }^{2}$ Saint \\ Peter Hospital, Rome, Italy; ${ }^{3}$ Hospital of \\ Monselice, Padua, Italy; ${ }^{4}$ University \\ Hospital of Rome, Rome, Italy; ${ }^{5}$ Hospital \\ of Siena, Siena, Italy; ${ }^{6}$ University of Bari, \\ Bari, Italy; ${ }^{7}$ RomaPro Center for Hip and \\ Knee Arthroplasty, polo Sanitario San \\ Feliciano, Rome, Italy
}

\begin{abstract}
The aim of this document is to provide a set of indications on the national best practice management of knee osteoarthritis based on an analysis of the existing literature and the contribution of experts in the field. During the first phase of the project, in agreement with the multidisciplinary panel of experts, the main guidelines on the topic were selected. Each guideline was assessed through the AGREEII system to identify their strong/weak points and a summary of the recommendations contained in the various documents was drawn up. The panel drew up a list of therapeutic options to be included in the document and some of these topics were selected for in-depth analysis and review. The search strategy for the required literature reviews was constructed using the PICOS approach. The results obtained from the literature reviews, the in-depth analyses conducted by the members of the scientific societies involved and the analysis of the existing guidelines enabled an initial draft of the consensus document to be elaborated. This document was examined at the consensus conference held on 28 May 2019, in the presence of a multidisciplinary group consisting of members of the various scientific societies involved. Single recommendations were discussed in work groups with a view to combining the indications given by the literature examined with the experience of the specialists involved. The recommendations discussed were then put to the vote in a plenary assembly. The final document contains 26 practice recommendations which leading specialists involved in the management of knee OA in Italy agree upon.
\end{abstract}

Keywords: knee osteoarthritis, conservative management, multidisciplinary consensus, Italy

\section{Introduction}

The difficulty in treating knee osteoarthritis derives from the intrinsic complexity of the disease, the clinical and pathophysiological heterogeneity of which emerges from the various attempts to define it. In fact, there is no single definition, just mere, lengthy descriptions of the possible causes, the pathophysiological processes and the clinical manifestations of the disease. ${ }^{1}$ Although arthritis is frequently a multiarticular disease that, in theory, is worthy of a holistic approach, the various recommendations and therapeutic algorithms promoted by the various scientific societies in the world always focus on a single articulation. Nevertheless, the treatment of knee osteoarthritis requires an approach shared by various specialists according to the main clinical manifestations and the functional status of the disease.

The latter, in particular, has an enormous social and economic impact on knee osteoarthritis, the actual weight of which is difficult to assess as it is the result of direct, indirect and intangible costs. As there is no precise overall assessment, a surrogate estimate could only be extrapolated from the direct cost of a single
Correspondence: Lorenzo Pradelli

Email I.pradelli@adreshe.com 
total knee arthroplasty, estimated on average in Italy at $€ 16,835$ euros for the five-year period $2001-2005$. $^{2}$ On the contrary, the suffering, pain and inconvenience caused to the patient by knee osteoarthritis throughout the course of this long-lasting disease cannot be quantified. It is therefore important that doctors responsible for providing care to individuals with knee osteoarthritis in Italy have, at their disposal, recommendations, based on rigorous scientific evidence, which, despite not being guidelines, may facilitate the treatment strategy of each individual patient. The ideal, desirable care pathway can come exclusively from a combination of the knowledge and skills of the various specialists in the field, physiatrists, rheumatologists and orthopaedists, who, at different times and with different methods, must interact during the course of the disease. To this aim, a panel of experts from the scientific societies of physiatrics (SIMFER), rheumatology (SIR), orthopaedics (SIOT) and osteoporosis (SIOMMMS) has been set up to elaborate up-to-date best practice recommendations relevant for the national context for the treatment of knee osteoarthritis, subsequently subjected to and validated by a group of physiatrists, rheumatologists and orthopaedists from all over Italy.

The methodology followed does not always follow established standards in clinical practice guideline development. The aim of the work behind this document was rather to define a national set of best practice recommendations assuming a multidisciplinary, pragmatic, and locally focused point of view. Where existing updated specialist guidelines were available and in full agreement, no further literature search or analysis was conducted these were undertaken only where evidence-based guideline recommendations were either conflicting or not updated. All recommendations are based on secondary use of data already in the public domain,; thus,no ethics approval was needed. More methodological details are provided in Appendix

We believe that the novelty of the present consensus on best practice in Italy relies on the extended enrollment of the main specialties involved in the management of patients with $\mathrm{OA}$ of the knee on the national ground, providing an overview of the approaches followed and recommended by leading Italian clinicians, and the evidence on which these approaches are based.

\section{Summary of Recommendations General Principles \\ Education and Lifestyle}

Patients with knee osteoarthritis should be provided with the information necessary to understand the disease and treatment objectives and to encourage them to make some changes to their lifestyle, by adopting behaviour that may have a beneficial effect or at least avoid worsening the condition. The strategies proposed must take account of the peculiar features of each individual patient and their social and family settings.

\section{Control of Body Weight}

Body weight control is strongly recommended in patients with knee osteoarthritis. Obese or overweight patients should follow a weight loss program following an adequate multidisciplinary assessment.

It is important to inform patients with a normal weight of the importance of maintaining their weight within the normal range.

\section{Conservative Treatments}

\section{Physical Agents}

Consider the use of physical agents for the treatment of knee osteoarthritis. Interferential therapy, laser therapy, magnetotherapy and application of vibrational energy seem to be the most effective physical agents.

\section{Therapeutic Physical Exercise}

Therapeutic exercise, which can even be performed at home, is recommended for treating patients with knee osteoarthritis.

\section{Mind-Body Exercises}

Mind-body exercises (such as Hatha Yoga, Tai Chi Qigong and Tai Chi Sun style) can be taken into consideration as a therapeutic approach for patients with knee osteoarthritis.

\section{Muscle-Strengthening Exercises}

Muscle-strengthening exercises (with or without other types of therapeutic exercises), with specific characteristics (type of resistance, type of contractions, method of supervision, intensity and duration of exercise program) can be indicated to treat knee osteoarthritis. 


\section{Aerobic Exercises}

A short-term program of aerobic exercises (with or without muscle-strengthening exercises) can be considered in order to reduce pain, improve physical function and quality of life of people with knee osteoarthritis.

\section{Hydrokinesitherapy}

Hydrokinesitherapy can be used for patients with knee osteoarthritis.

\section{Balneotherapy}

Balneotherapy represents a complementary approach with short and long-term efficacy in terms of pain relief and articular function in patients with knee osteoarthritis. It is indicated above all in patients with comorbidities and/or contraindications for pharmacological treatment.

\section{Acupuncture}

At present, there is little reliable evidence on the use of acupuncture in the management of patients with knee osteoarthritis.

\section{Patellar Taping}

At present, there is little reliable evidence on the use of patellar taping in the management of patients with knee osteoarthritis.

\section{Intra-Articular Injections}

Intra-Articular Injections - Hyaluronic Acid

Intra-articular injections of hyaluronic acid are useful in the treatment of patients with knee osteoarthritis. The procedure can be repeated safely.

\section{Intra-Articular Injections - Corticosteroids}

Intra-articular injections of corticosteroids are useful for short-term treatment of pain symptoms in patients with knee osteoarthritis. Particular attention should be paid to the potential damage caused by repeated use.

\section{Intra-Articular Injections - Platelet-Rich Plasma}

At present, there is little reliable evidence on the use of intra-articular injections of platelet-rich plasma in the management of patients with knee osteoarthritis. No major safety problems have emerged up to now.

\section{SYSADOAs - Slow-Acting Systemic Drugs SYSADOAs - Glucosamine}

Glucosamine can be used for continuous treatment of the symptoms (pain and function) of knee osteoarthritis for at least 12 months. Data available in the literature suggest longterm efficacy of the prescription drug glucosamine sulfate but not for formulations containing other glucosamine salts.

\section{SYSADOAs - Chondroitin}

Chondroitin can be considered for the treatment of symptoms (pain and function) in patients with knee osteoarthritis in the short term only (up to 6 months).

\section{SYSADOAs - Avocado Soybean Unsaponifiables}

The use of avocado soybean unsaponifiables is not supported by any scientific evidence.

\section{Pharmacological Treatment}

\section{Oral Non-Steroidal Anti-Inflammatory Drugs}

The use of non-steroidal anti-inflammatory drugs (NSAIDs), including COX-2 inhibitors, can be considered for patients with knee osteoarthritis. The drug chosen should be administered at the lowest effective dose on pain and function for a limited period of time, considering the patient's comorbidities and monitoring any adverse gastrointestinal, hepatic, cardiovascular and renal effects.

\section{Opioids}

The use of opioids can be considered for the treatment of pain in patients with knee osteoarthritis in which NSAIDs are ineffective or contraindicated.

\section{Paracetamol}

Administration of paracetamol can be considered in patients with knee osteoarthritis, but only slight pain relief is obtained.

\section{Topical Preparations}

The application of NSAIDs can be taken into consideration.

The use of other topical preparations is not recommended in patients with knee osteoarthritis due to the lack of scientific evidence.

\section{Mechanical Aids}

Walking Aids

The use of walking aids (walking sticks, crutches, walking frames, etc.) may be appropriate for selected patients, taking into consideration also their individual comorbidities, preferences and capabilities. Patients must be taught to use prescribed aids to ensure their efficacy and safety.

\section{Braces}

At present, there is little reliable evidence on the use of 
knee braces for the management of patients with knee osteoarthritis.

\section{Foot Orthoses}

At present, there is little reliable evidence on the use of foot orthoses for the management of patients with knee osteoarthritis.

\section{Non-Substitutive Surgical Procedures}

\section{Arthroscopic Surgery}

Routine arthroscopic surgery (debridement, meniscectomy and cartilage repair techniques) is not recommended.

In mild/moderate knee osteoarthritis, arthroscopic surgery can be considered for treating the causes of mechanical articular blockage, above all in patients unresponsive to conservative treatment.

\section{Knee Realignment Osteotomy}

Knee realignment osteotomy (tibial/femoral) can be proposed for selected patients (eg active adults not overweight) with mild to moderate single-region symptomatic knee osteoarthritis.

\section{Indications for Substitute Surgery}

Substitutive surgery should be taken into consideration for patients with severe symptoms and unresponsive to pharmacological and conservative treatments.

The most significant criteria to be considered for a knee prosthesis are:

-Joint pain with limited function

-Proven structural damage

- Failure of pharmacological/conservative treatments

-Deterioration in quality of life

-Significant subjective suffering

\section{Elaboration of the Consensus Document}

The aim of this document is to provide a set of indications on the management of knee osteoarthritis based on an analysis of the existing literature and the contribution of experts in the field.

During the first phase of the project, in agreement with the multidisciplinary panel of experts, the main guidelines on the topic were selected (Table 1). Each guideline was assessed through the AGREEII system to identify their strong/weak points and a summary of the recommendations contained in the various documents was drawn up.
Table I Selected Guidelines

\begin{tabular}{|l|l|}
\hline AAOS $^{25}$ & $\begin{array}{l}\text { Treatment of osteoarthritis of the knee evidence-based } \\
\text { guideline 2nd edition. 20I3 }\end{array}$ \\
\hline VA/ & $\begin{array}{l}\text { Clinical practice guideline for the non-surgical } \\
\text { management of hip \& knee osteoarthritis. Version } \\
\text { I.0-20I4 }\end{array}$ \\
\hline ESCEO $^{96}$ & $\begin{array}{l}\text { An algorithm recommendation for the management of } \\
\text { knee osteoarthritis in Europe and internationally: } \\
\text { A report from a task force of the European Society for } \\
\text { Clinical and Economic Aspects of Osteoporosis and } \\
\text { Osteoarthritis - 20I4 }\end{array}$ \\
\hline OARSI $^{26}$ & $\begin{array}{l}\text { Guidelines for the non-surgical management of knee } \\
\text { osteoarthritis - 20I4 }\end{array}$ \\
\hline NICE $^{27}$ & $\begin{array}{l}\text { Osteoarthritis: the care and management of } \\
\text { osteoarthritis - 20I4 }\end{array}$ \\
\hline ACR $^{94}$ & $\begin{array}{l}\text { Recommendations for the Use of Nonpharmacologic } \\
\text { and Pharmacologic Therapies in Osteoarthritis of the } \\
\text { Hand, Hip, and Knee - 20I2 }\end{array}$ \\
\hline RACGP $^{17}$ & $\begin{array}{l}\text { Guideline for the management of knee and hip } \\
\text { osteoarthritis. Second edition - 20I8. Royal Australian } \\
\text { College of General Practitioners. }\end{array}$ \\
\hline
\end{tabular}

The panel drew up a list of therapeutic operations to be included in the document and some of these topics were selected for in-depth analysis and review (Appendix 1).

Parameters of the "PICOS" model for elaborating clinical questions were established: Patients: Diagnosis of idiopathic or secondary knee osteoarthritis (with possible involvement of other regions), irrespective of the Kellgren-Lawrence grade. Possible presence of other comorbidities. Age $\geq 18$ years.

Interventions: Indicated by the panel

Comparisons: Any

Outcomes: Pain, function, quality of life

Studies: Meta-analysis, systematic reviews of EMBASE, Cochrane, PubMed. Period of time: January 2017-March 2019.

Appendix 2 indicates the characteristics of the literature research conducted to update the topics selected.

The results obtained from the literature reviews, the indepth analyses conducted by the members of the scientific societies involved and the analysis of the existing guidelines enabled an initial draft of the consensus document to be elaborated.

This document was examined at the consensus conference held on 28 May 2019, in the presence of 
a multidisciplinary group consisting of members of the various scientific societies involved.

Single recommendations were discussed in work groups with a view to combining the indications given in the literature examined with the experience of the specialists involved. The recommendations discussed were then put to the vote in a plenary assembly: each member was called to express their degree of consensus anonymously by choosing between "full agreement", "sufficient agreement", "slight disagreement", "total disagreement" (Figure 1 - the results of each vote are indicated in the Consensus table section).

The consensus was defined as a percentage of favorable votes (full agreement and sufficient agreement) by $66 \%$ or more of the participants (Table 2). All the recommendations except one were approved (see the Unapproved recommendations section).

\section{General Principles Education and Life Style Recommendation}

Patients with knee osteoarthritis should be provided with the information necessary to understand the disease and treatment objectives and to encourage them to make some changes to their lifestyle, by adopting behaviour that may have a beneficial effect or at least avoid worsening the condition. The strategies proposed must take account of the peculiar features of each individual patient and their social and family settings.
Statement elaborated on the basis of RACGP,${ }^{17}$ NICE$\mathrm{CG}_{177^{27}}$ and OARSI ${ }^{26}$ guidelines.

\section{Control of Body Weight}

\section{Recommendation}

Body weight control is strongly recommended in patients with knee osteoarthritis. Obese or overweight patients should follow a weight loss program following an adequate multidisciplinary assessment.

It is important to inform patients with a normal weight of the importance of maintaining their weight within the normal range.

Statement elaborated on the basis of RACGP $^{17}$ guidelines.

\section{Comment}

The Australian guidelines recommend a minimum weight loss of $5-7.5 \%$ of the initial weight; as large a weight loss as possible is, in any case, desirable given the relationship between weight loss and the possible benefits.

The experts underline the importance of the multidisciplinary approach, including a metabolic and cardiovascular assessment, so as to propose a program that adapts best to the patient's peculiar features.

\section{Conservative Treatments}

\section{Physical Agents}

Recommendation

Consider the use of physical agents for the treatment of knee osteoarthritis. Interferential therapy, laser therapy,

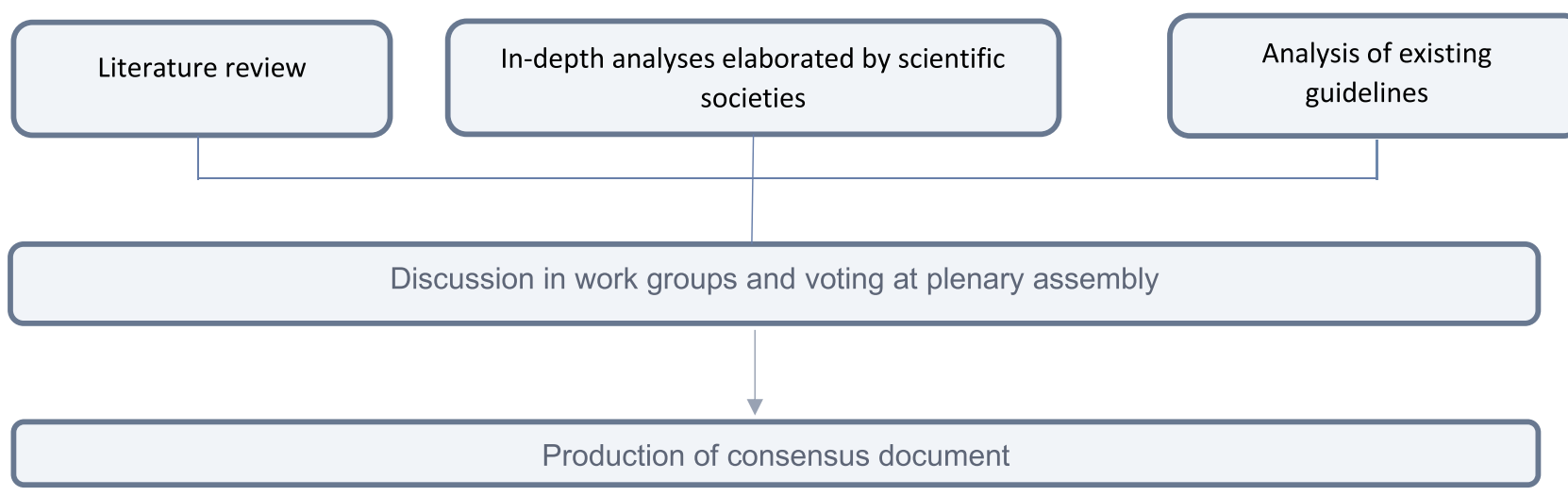

Figure I Elaboration process of the consensus document. 
Table 2 Consensus Table - Consensus Reached with 66\% Favourable Votes

\begin{tabular}{|c|c|c|c|c|c|}
\hline Recommendation & $\begin{array}{c}\text { Full } \\
\text { Agreement }\end{array}$ & $\begin{array}{c}\text { Sufficient } \\
\text { Agreement }\end{array}$ & $\begin{array}{c}\text { Slight } \\
\text { Disagreement }\end{array}$ & $\begin{array}{c}\text { Total } \\
\text { Disagreement }\end{array}$ & Consensus \\
\hline $\begin{array}{l}\text { General principles - Education and life style } \\
\text { Patients with knee osteoarthritis should be provided } \\
\text { with the information necessary to understand the } \\
\text { disease and treatment objectives and to encourage } \\
\text { them to make some changes to their life style, by } \\
\text { adopting behaviour that may have a beneficial effect } \\
\text { or at least avoid worsening the condition. The } \\
\text { strategies proposed must take account of the } \\
\text { peculiar features of each individual patient and their } \\
\text { social and family setting. }\end{array}$ & $76.3 \%$ & $18.4 \%$ & $0.0 \%$ & $5.3 \%$ & $\begin{array}{c}\text { Recommendation } \\
\text { approved }\end{array}$ \\
\hline $\begin{array}{l}\text { General principles - Body weight control } \\
\text { Body weight control is strongly recommended in } \\
\text { patients with knee osteoarthritis. Obese or } \\
\text { overweight patients should follow a weight loss } \\
\text { program following an adequate multidisciplinary } \\
\text { assessment. It is important to inform patients with } \\
\text { a normal weight of the importance of maintaining } \\
\text { their weight within the normal range. }\end{array}$ & $92.1 \%$ & $5.3 \%$ & $0.0 \%$ & $2.6 \%$ & $\begin{array}{c}\text { Recommendation } \\
\text { approved }\end{array}$ \\
\hline $\begin{array}{l}\text { Conservative treatments - Physical agents } \\
\text { Consider the use of physical agents for the treatment } \\
\text { of knee osteoarthritis. Interferential therapy, laser } \\
\text { therapy, magnetotherapy and application of } \\
\text { vibrational energy seem to be the most effective } \\
\text { physical agents. }\end{array}$ & $40.5 \%$ & $29.7 \%$ & $10.8 \%$ & $18.9 \%$ & $\begin{array}{c}\text { Recommendation } \\
\text { approved }\end{array}$ \\
\hline $\begin{array}{l}\text { Conservative treatments - Therapeutic exercise } \\
\text { Therapeutic exercise, which can even be performed } \\
\text { at home, is recommended for treating patients with } \\
\text { knee osteoarthritis. }\end{array}$ & $75.0 \%$ & $20.0 \%$ & $5.0 \%$ & $0.0 \%$ & $\begin{array}{c}\text { Recommendation } \\
\text { approved }\end{array}$ \\
\hline $\begin{array}{l}\text { Conservative treatments - Mind-body exercises } \\
\text { Mind-body exercises (such as Hatha Yoga, Tai Chi } \\
\text { Qigong and Tai Chi Sun style) can be taken into } \\
\text { consideration as a therapeutic approach for patients } \\
\text { with knee osteoarthritis. }\end{array}$ & $27.5 \%$ & $40.0 \%$ & $15.0 \%$ & $17.5 \%$ & $\begin{array}{c}\text { Recommendation } \\
\text { approved }\end{array}$ \\
\hline $\begin{array}{l}\text { Conservative treatments - Muscle-strengthening } \\
\text { exercises } \\
\text { Muscle-strengthening exercises (with or without } \\
\text { other types of therapeutic exercises), with specific } \\
\text { characteristics (type of resistance, type of } \\
\text { contractions, method of supervision, intensity and } \\
\text { duration of exercise program) can be indicated to } \\
\text { treat knee osteoarthritis. }\end{array}$ & $63.2 \%$ & $23.7 \%$ & $13.2 \%$ & $0.0 \%$ & $\begin{array}{c}\text { Recommendation } \\
\text { approved }\end{array}$ \\
\hline $\begin{array}{l}\text { Conservative treatments - Aerobic exercises } \\
\text { A short-term program of aerobic exercises (with or } \\
\text { without muscle-strengthening exercises) can be } \\
\text { considered in order to reduce pain, improve physical } \\
\text { function and quality of life of people with knee } \\
\text { osteoarthritis. }\end{array}$ & $51.3 \%$ & $30.8 \%$ & $10.3 \%$ & $7.7 \%$ & $\begin{array}{c}\text { Recommendation } \\
\text { approved }\end{array}$ \\
\hline
\end{tabular}

(Continued) 
Table 2 (Continued).

\begin{tabular}{|c|c|c|c|c|c|}
\hline Recommendation & $\begin{array}{c}\text { Full } \\
\text { Agreement }\end{array}$ & $\begin{array}{c}\text { Sufficient } \\
\text { Agreement }\end{array}$ & $\begin{array}{c}\text { Slight } \\
\text { Disagreement }\end{array}$ & $\begin{array}{c}\text { Total } \\
\text { Disagreement }\end{array}$ & Consensus \\
\hline $\begin{array}{l}\text { Conservative treatments - Hydrokinesitherapy } \\
\text { Hydrokinesitherapy can be used for patients with } \\
\text { knee osteoarthritis. }\end{array}$ & $72.5 \%$ & $25.0 \%$ & $2.5 \%$ & $0.0 \%$ & $\begin{array}{c}\text { Recommendation } \\
\text { approved }\end{array}$ \\
\hline $\begin{array}{l}\text { Conservative treatments - Balneotherapy } \\
\text { Balneotherapy represents a complementary approach } \\
\text { with short and long-term efficacy in terms of pain } \\
\text { relief and articular function in patients with knee } \\
\text { osteoarthritis. It is indicated above all in patients with } \\
\text { comorbidities and/or contraindications for } \\
\text { pharmacological treatment. }\end{array}$ & $52.5 \%$ & $22.5 \%$ & $12.5 \%$ & $12.5 \%$ & $\begin{array}{c}\text { Recommendation } \\
\text { approved }\end{array}$ \\
\hline $\begin{array}{l}\text { Conservative treatments - Acupuncture } \\
\text { At present, there is little reliable evidence on the use } \\
\text { of acupuncture in the management of patients with } \\
\text { knee osteoarthritis. }\end{array}$ & $50.0 \%$ & $31.6 \%$ & $5.3 \%$ & $13.2 \%$ & $\begin{array}{c}\text { Recommendation } \\
\text { approved }\end{array}$ \\
\hline $\begin{array}{l}\text { Conservative treatments - Patellar taping } \\
\text { At present, there is little reliable evidence on the use } \\
\text { of patellar taping in the management of patients with } \\
\text { knee osteoarthritis. }\end{array}$ & $57.9 \%$ & $28.9 \%$ & $2.6 \%$ & $10.5 \%$ & $\begin{array}{c}\text { Recommendation } \\
\text { approved }\end{array}$ \\
\hline $\begin{array}{l}\text { Intra-articular injections - Hyaluronic acid } \\
\text { Intra-articular injections of hyaluronic acid are useful } \\
\text { in the treatment of patients with knee osteoarthritis. } \\
\text { The procedure can be repeated safely. }\end{array}$ & $55.0 \%$ & $30.0 \%$ & $7.5 \%$ & $7.5 \%$ & $\begin{array}{c}\text { Recommendation } \\
\text { approved }\end{array}$ \\
\hline $\begin{array}{l}\text { Intra-articular injections - Corticosteroids } \\
\text { Intra-articular injections of corticosteroids are useful } \\
\text { for short-term treatment of pain symptoms in } \\
\text { patients with knee osteoarthritis. Particular attention } \\
\text { should be paid to the potential damage caused by } \\
\text { repeated use. }\end{array}$ & $63.4 \%$ & $26.8 \%$ & $4.9 \%$ & $4.9 \%$ & $\begin{array}{c}\text { Recommendation } \\
\text { approved }\end{array}$ \\
\hline $\begin{array}{l}\text { Intra-articular injections - Platelet-rich plasma } \\
\text { At present, there is little reliable evidence on the use } \\
\text { of intra-articular injections of platelet-rich plasma in } \\
\text { the management of patients with knee osteoarthritis. } \\
\text { No major safety problems have emerged up to now. }\end{array}$ & $60.5 \%$ & $31.6 \%$ & $2.6 \%$ & $5.3 \%$ & $\begin{array}{c}\text { Recommendation } \\
\text { approved }\end{array}$ \\
\hline $\begin{array}{l}\text { SYSADOAs - Glucosamine } \\
\text { Glucosamine can be used for continuous treatment } \\
\text { of the symptoms (pain and function) of knee } \\
\text { osteoarthritis for at least } 12 \text { months. The data } \\
\text { available in the literature suggest long-term efficacy } \\
\text { for the prescription drug glucosamine sulfate but not } \\
\text { for formulations containing other glucosamine salts. }\end{array}$ & $52.5 \%$ & $30.0 \%$ & $5.0 \%$ & $12.5 \%$ & $\begin{array}{c}\text { Recommendation } \\
\text { approved }\end{array}$ \\
\hline $\begin{array}{l}\text { SYSADOAs - Chondroitin } \\
\text { Chondroitin can be considered for the treatment of } \\
\text { symptoms (pain and function) in patients with knee } \\
\text { osteoarthritis in the short term only (up to } 6 \\
\text { months). }\end{array}$ & $34.3 \%$ & $48.6 \%$ & $5.7 \%$ & $11.4 \%$ & $\begin{array}{c}\text { Recommendation } \\
\text { approved }\end{array}$ \\
\hline
\end{tabular}

(Continued) 
Table 2 (Continued).

\begin{tabular}{|c|c|c|c|c|c|}
\hline Recommendation & $\begin{array}{c}\text { Full } \\
\text { Agreement }\end{array}$ & $\begin{array}{c}\text { Sufficient } \\
\text { Agreement }\end{array}$ & $\begin{array}{c}\text { Slight } \\
\text { Disagreement }\end{array}$ & $\begin{array}{c}\text { Total } \\
\text { Disagreement }\end{array}$ & Consensus \\
\hline $\begin{array}{l}\text { SYSADOAs - Diacerein } \\
\text { Diacerein can only be considered for short-term } \\
\text { treatment ( }<3 \text { months) in patients with knee } \\
\text { osteoarthritis who can tolerate it. }\end{array}$ & $37.5 \%$ & $20.0 \%$ & $30.0 \%$ & $12.5 \%$ & $\begin{array}{c}\text { Consensus NOT } \\
\text { reached }\end{array}$ \\
\hline $\begin{array}{l}\text { SYSADOAs -Avocado soybean unsaponifiables } \\
\text { The use of avocado soybean unsaponifiables is not } \\
\text { supported by any scientific evidence. }\end{array}$ & $79.5 \%$ & $7.7 \%$ & $5.1 \%$ & $7.7 \%$ & $\begin{array}{c}\text { Recommendation } \\
\text { approved }\end{array}$ \\
\hline $\begin{array}{l}\text { Pharmacological therapy - NSAIDs } \\
\text { The use of non-steroidal anti-inflammatory drugs } \\
\text { (NSAIDs), including COX-2 inhibitors, can be } \\
\text { considered for patients with knee osteoarthritis. The } \\
\text { drug chosen should be administered at the lowest } \\
\text { effective dose on pain and function for a limited } \\
\text { period of time, considering the patient's } \\
\text { comorbidities and monitoring any adverse } \\
\text { gastrointestinal, hepatic, cardiovascular and renal } \\
\text { effects. }\end{array}$ & $89.2 \%$ & $10.8 \%$ & $0.0 \%$ & $0.0 \%$ & $\begin{array}{c}\text { Recommendation } \\
\text { approved }\end{array}$ \\
\hline $\begin{array}{l}\text { Pharmacological therapy - Opioids } \\
\text { The use of opioids can be considered for the } \\
\text { treatment of pain in patients with knee osteoarthritis } \\
\text { in which NSAIDs are ineffective or contraindicated. }\end{array}$ & $71.1 \%$ & $26.3 \%$ & $2.6 \%$ & $0.0 \%$ & $\begin{array}{c}\text { Recommendation } \\
\text { approved }\end{array}$ \\
\hline $\begin{array}{l}\text { Pharmacological therapy - Paracetamol } \\
\text { The administration of paracetamol can be considered } \\
\text { in patients with knee osteoarthritis, but only slight } \\
\text { pain relief is obtained. }\end{array}$ & $51.3 \%$ & $30.8 \%$ & $10.3 \%$ & $7.7 \%$ & $\begin{array}{c}\text { Recommendation } \\
\text { approved }\end{array}$ \\
\hline $\begin{array}{l}\text { Pharmacological therapy - Topical preparations } \\
\text { The application of NSAIDs can be taken into } \\
\text { consideration. } \\
\text { The use of other topical preparations is not } \\
\text { recommended in patients with knee osteoarthritis } \\
\text { due to the lack of scientific evidence. }\end{array}$ & $59.5 \%$ & $24.3 \%$ & $13.5 \%$ & $2.7 \%$ & $\begin{array}{c}\text { Recommendation } \\
\text { approved }\end{array}$ \\
\hline $\begin{array}{l}\text { Walking aids } \\
\text { The use of walking aids (walking stick, crutches, } \\
\text { walking frame, etc.) may be appropriate for selected } \\
\text { patients, taking into consideration also their } \\
\text { individual comorbidities, preferences and capabilities. } \\
\text { The patients must be taught to use the prescribed } \\
\text { aids so as to ensure their efficacy and safety. }\end{array}$ & $84.2 \%$ & $13.2 \%$ & $0.0 \%$ & $2.6 \%$ & $\begin{array}{c}\text { Recommendation } \\
\text { approved }\end{array}$ \\
\hline $\begin{array}{l}\text { Walking aids - Braces } \\
\text { At present, there is little reliable evidence on the use } \\
\text { of knee braces for the management of patients with } \\
\text { knee osteoarthritis. }\end{array}$ & $52.8 \%$ & $38.9 \%$ & $2.8 \%$ & $5.6 \%$ & $\begin{array}{c}\text { Recommendation } \\
\text { approved }\end{array}$ \\
\hline
\end{tabular}

(Continued) 
Table 2 (Continued).

\begin{tabular}{|c|c|c|c|c|c|}
\hline Recommendation & $\begin{array}{c}\text { Full } \\
\text { Agreement }\end{array}$ & $\begin{array}{c}\text { Sufficient } \\
\text { Agreement }\end{array}$ & $\begin{array}{c}\text { Slight } \\
\text { Disagreement }\end{array}$ & $\begin{array}{c}\text { Total } \\
\text { Disagreement }\end{array}$ & Consensus \\
\hline $\begin{array}{l}\text { Walking aids - Foot orthoses } \\
\text { At present, there is little reliable evidence on the use } \\
\text { of foot orthoses for the management of patients with } \\
\text { knee osteoarthritis. }\end{array}$ & $72.2 \%$ & $25.0 \%$ & $0.0 \%$ & $2.8 \%$ & $\begin{array}{c}\text { Recommendation } \\
\text { approved }\end{array}$ \\
\hline $\begin{array}{l}\text { Conservative surgery - Arthroscopic surgery } \\
\text { Routine arthroscopic surgery (debridement, } \\
\text { meniscectomy and cartilage repair methods) is not } \\
\text { recommended. } \\
\text { Arthroscopic surgery can be considered for treating } \\
\text { the causes of mechanical articular blockage, above all } \\
\text { in patients unresponsive to conservative treatment } \\
\text { and suffering from mild/moderate knee } \\
\text { osteoarthritis. }\end{array}$ & $68.4 \%$ & $28.9 \%$ & $2.6 \%$ & $0.0 \%$ & $\begin{array}{c}\text { Recommendation } \\
\text { approved }\end{array}$ \\
\hline $\begin{array}{l}\text { Conservative surgery - Realignment osteotomy } \\
\text { Knee realignment osteotomy (tibial/femoral) can be } \\
\text { proposed to selected patients (eg active adults not } \\
\text { overweight) with mild to moderate single-region } \\
\text { symptomatic knee osteoarthritis. }\end{array}$ & $72.2 \%$ & $25.0 \%$ & $2.8 \%$ & $0.0 \%$ & $\begin{array}{c}\text { Recommendation } \\
\text { approved }\end{array}$ \\
\hline $\begin{array}{l}\text { Indications for substitute surgery } \\
\text { Substitutive surgery should be taken into } \\
\text { consideration for patients with severe symptoms and } \\
\text { unresponsive to pharmacological and conservative } \\
\text { treatments. } \\
\text { The most significant criteria to be considered for } \\
\text { a knee prosthesis are: } \\
\text {-Joint pain with limited function } \\
\text {-Proven structural damage } \\
\text { - Failure of pharmacological/conservative treatments } \\
\text {-Deterioration in quality of life } \\
\text {-Significant subjective suffering }\end{array}$ & $83.3 \%$ & $16.2 \%$ & $0 \%$ & $0 \%$ & $\begin{array}{c}\text { Recommendation } \\
\text { approved }\end{array}$ \\
\hline
\end{tabular}

magnetotherapy and application of vibrational energy seem to be the most effective physical agents.

\section{Comment}

As far as the physical means are concerned, the guidelines currently available are rather vague, because they often use the generic term "electroanalgesia", without specifying the parameters of the current used.

The instrumental physical therapy is based on the use of physical agents or means, such as heat, light, electricity, electromagnetic waves, ultrasound waves, etc., for the treatment of various disorders of the musculoskeletal system.

The principal forms of instrumental physical treatment are summarized in Table 3. These treatments adopt parameters that regulate the supply of energy administered and that require a prescription from a doctor specialized in Physical and Rehabilitation Medicine. .,4 $^{3}$

\section{Laser Therapy}

Laser therapy consists in using the effects produced by the electromagnetic energy generated by two sources of laser light for therapeutic purposes in the field of physiotherapy (L.A.S.E.R. = Light Amplification by Stimulated Emission of Radiation).

\section{Ultrasound}

Ultrasound is sound waves with frequencies higher than the audible limit of human hearing.

Ultrasonic irradiation thus generates a highly intense micromassage that penetrates deep into the tissue. 
Table 3 Classification of Agents According to Their Prevalent Effect on Tissues

\begin{tabular}{|l|l|l|}
\hline Energy & Physical Agent & Treatments \\
\hline $\begin{array}{l}\text { Electromagnetic } \\
\text { energy }\end{array}$ & $\begin{array}{l}\text { Electric current, electromagnetic } \\
\text { fields. }\end{array}$ & TENS, IFC, microcurrents, HVPC, F.E.S., NMES, PEMF, magnetic fields \\
\hline Thermal energy & Micro-waves, short waves. & $\begin{array}{l}\text { Hyperthermia, microwave diathermia, short-wave diathermia, CRet, laser } \\
\text { therapy. }\end{array}$ \\
\hline Mechanical energy & Mechanical sound waves. & Shock waves, ultrasound, cryoultrasound \\
\cline { 2 - 3 } & Vibrations. & Vibrational energy \\
\hline
\end{tabular}

Abbreviations: TENS, transcutaneous electrical nerve stimulation; IFC, interferential current; HVPC, high voltage pulsed current; FES, functional electrical stimulation; NMES, neuromuscular electrical stimulation; PEMF, pulsed electromagnetic field therapy; CRet, capacitive and resistive energy transfer.

The vibration, shock and friction of the cell and intracellular structures generate heat, so ultrasound has a thermal effect as well as a mechanical effect.

\section{Tens}

TENS is the most widely used method of electrotherapy in physiotherapy for analgesic-antalgic purposes in the treatment of pain, extremely effective for the treatment of many neurological, osteoarticular, ligament and tendon diseases. TENS stands for "Transcutaneous Electric Nervous Stimulation" in that the technique consists in applying to the skin some particular electrical pulses that only stimulate the tactile sensitivity nerve fibres situated directly under the skin by means of electroconductive plates. The nerve impulses produced in this way are transmitted, through the sensory nerves, up the spinal cord, thus blocking "gateway to pain" (gate control process).

\section{Heat Therapy}

Thermal energy can be transmitted to the tissues through various mechanisms: conduction (physical contact between surfaces), convection (for liquids and gases), conversion (absorption of electromagnetic energy) and irradiation. Each treatment can also propagate its effects to deeper tissues or act on more superficial structures.

\section{Physical Agents - Literature Review}

The literature reviews concerning the various physical means and the authors' conclusions are examined here below.

\section{Interferential Current (IFC)}

Results have shown that IFC is the only significantly effective treatment in terms of pain intensity and pain score at the last follow-up time with respect to the control group (blank or sham). In the meantime, IFC is likely to be the best treatment option among the six methods of treatment for pain relief.

These results change little in the analysis of sensitivity. However, the evidence of heterogeneity and limited sample size of some studies could pose a potential threat to the validity of the results. Although the level of recommendation of the other SE therapies is uncertain (h-TENS) or inappropriate (1-TENS, NMES, PES and NIN) for pain relief, it is probable that none of the methods is dangerous. ${ }^{5}$

\section{Short-Wave Diathermia}

The systematic review ${ }^{6}$ considered reveals that there is a moderate pain-relieving effect in the short term, above all with pulsed and non-continuous waves.

\section{Neuromuscular Electrostimulation (NMES)}

Reduces pain symptoms; increases muscle strength; does not improve functional performance. The benefit is “ambiguous". Evidence D. ${ }^{7}$

A narrative review of $2017^{95}$ states that this technique could bring a benefit in terms of muscle strengthening (without specifying whether this is transformed into a pain-relieving or functional benefit).

\section{Vibrational Energy}

The study by Benedetti et $\mathrm{al}^{8}$ reveals an increase in the ROM (range of motion), functional performance and reduction of the pain.

\section{Laser}

Benefit in pain at rest, during activities and in articular stiffness.

Despite some positive results, this meta-analysis provides no data on how the efficacy of LLLT is influenced by 
important factors: wavelength, energy density, duration of treatment, number of treatment sessions, gravity of KOA and site of application. ${ }^{9}$

\section{Magnetotherapy}

Current evidence suggests that treatment with electromagnetic fields may give a moderate benefit to patients with knee osteoarthritis in terms of pain relief. Individuals who have received treatment with electromagnetic fields have experienced a reduction in pain of 15 points more than individuals receiving treatment with a placebo $(15 \%$ improvement). ${ }^{10}$

The authors also report an improvement in functional performance and pain relief (ICNIRP: International Commission on non-ionizing radiation protection). ${ }^{11}$

\section{Power Laser}

The use of power laser improves pain relief, functional performance and articular stiffness. A reduction in thickness of synovial inflammation was also observed during the ultrasound scan. ${ }^{12}$

\section{Transcutaneous Electrical Nerve Stimulation (TENS)}

Despite more than 20 years of clinical research, there is a lack of adequate proof supporting the use of any type of transcutaneous electric nerve stimulation in patients with knee osteoarthritis. The effects on pain and knee function are potentially significant from a clinical point of view and deserve further clinical assessment.

Despite the fairly good results obtained in the forest plots of the meta-analysis, the reviewers are very cautious, due to the heterogeneity of the studies and the small sample size. $^{13}$

\section{Ultrasound (US)}

Ultrasound therapy may be useful for patients with knee osteoarthritis. Due to the poor quality of the proof, however, there is uncertainty over the size of the effects on pain and function. Ultrasound therapy is widely used for its potential benefits on pain and knee function, which may be significant from the clinical point of view. The reviewers quantify the pain relief, in terms of a $50 \%$ reduction of pain, with a number needed to treat of $6 .^{14}$

The study conducted by Zhang et $\mathrm{al}^{15}$ shows a reduction in pain and increase in functional performance. The treatment studied is considered safe. No difference was found between the application of pulsed and continuous ultrasound and in the duration of treatment (4-8 weeks).

\section{Therapeutic Physical Exercise \\ Recommendation}

Therapeutic exercise, which can even be performed at home, is recommended for treating patients with knee osteoarthritis.

\section{Comment}

As far as therapeutic physical exercise is concerned, the guidelines examined all recommended physical exercise, without however specifying the method, frequency or intensity. Only the "Ottawa panel clinical practice guidelines for the management of knee osteoarthritis" specify the various kinds of exercise with their levels of evidence. $^{37-39}$

The work group underlines that therapeutic exercise is not the first choice among conservative treatments for the acute inflammatory phase of knee osteoarthritis.

\section{Mind-Body Exercises \\ Recommendation}

Mind-body exercises (such as Hatha Yoga, Tai Chi Qigong and Tai Chi Sun style) can be taken into consideration as a therapeutic approach for patients with knee osteoarthritis.

Statement elaborated on the basis of Ottawa panel guidelines. Part $1^{3735}$

\section{Comment}

The mind-body exercises combine body movements, meditation and breathing techniques in order to improve, strength, balance, flexibility and general wellbeing. ${ }^{16}$

According to Ottawa panel indications, Hatha Yoga gives pain relief and improves the self-assessed physical function.

Positive results in terms of pain and function were obtained by Tai Chi style and Tai Chi Qigong Sun, the latter also demonstrated an improvement in the quality of life.

\section{Muscle- Strengthening Exercises Recommendation}

Muscle-strengthening exercises (with or without other types of therapeutic exercises), with specific characteristics (type of resistance, type of contractions, method of supervision, intensity and duration of exercise program) can be indicated to treat knee osteoarthritis.

Statement elaborated on the basis of Ottawa panel guidelines Part 2. ${ }^{36}$ 
In the In-depth analyses section main topics related to muscle exercises are discussed; for a more complete description, see the specialist texts.

\section{Aerobic Exercises}

\section{Recommendation}

A short-term program of aerobic exercises (with or without muscle-strengthening exercises) can be considered in order to reduce the pain, improve physical function and quality of life of people with knee osteoarthritis.

Statement elaborated on the basis of Ottawa panel guidelines. Part 3. ${ }^{37,39}$

\section{Hydrokinesitherapy Recommendation}

Hydrokinesitherapy can be used for patients with knee osteoarthritis.

Statement elaborated on the basis of VA/DoD guidelines. ${ }^{18}$

\section{Balneotherapy}

\section{Recommendation}

Balneotherapy represents a complementary approach with short and long-term efficacy against pain and articular function in patients with knee osteoarthritis. It is indicated above all in patients with comorbidities and/or contraindications for pharmacological treatment.

Statement elaborated on the basis of an in-depth analysis conducted by SIR.

\section{Comment}

The term Balneotherapy indicates the use of thermal spa treatments (mineral water, mud or other peloids) for therapeutic purposes. It should therefore be distinguished from hydrotherapy in which only drinking water is used. ${ }^{22}$

Balneotherapy is indicated primarily for chronic degenerative diseases, such as osteoarthritis. Several systematic reviews and randomized placebo-controlled studies on the use of Balneotherapy in knee osteoarthritis have demonstrated a significant effect on pain, functional performance and quality of life. ${ }^{19-24,21-23}$ Long-term trials have revealed persistent clinical efficacy in time and, in any case, for more than 3 months. ${ }^{19}$ The size of the sample examined, the rarity of randomized double-blind controlled studies and their scientific quality still constitute limiting factors for a definitive scientific validation of Balneotherapy in knee osteoarthritis. The data available enable this technique, however, to be considered a useful option as complementary therapy above all in the presence of comorbidities, contraindications or intolerance to other types of treatment.

\section{Acupuncture}

\section{Recommendation}

At present, there is little reliable evidence on the use of acupuncture in the management of patients with knee osteoarthritis.

Statement elaborated on the basis of $\mathrm{RACGP}^{17}$ and NICE-CG177 ${ }^{27}$ guidelines.

\section{Patellar Taping \\ Recommendation}

At present, there is little reliable evidence on the use of patellar taping in the management of patients with knee osteoarthritis.

Statement elaborated on the basis of RACGP $^{17}$ guidelines.

\section{Intra-Articular Injections Intra-Articular Injections - Hyaluronic Acid}

\section{Recommendation}

Intra-articular injections of hyaluronic acid are useful in the treatment of patients with knee osteoarthritis. The procedure can be repeated safely.

\section{Comment}

Intra-articular injections of hyaluronic acid seem to bring a significant improvement in pain relief and functional performance for up to 6 months. ${ }^{34}$ The data concerning the long-term control of pain symptoms ( $\geq 12$ months) are not statistically significant. ${ }^{29}$

The sources considered indicate better results, in terms of pain relief for formulations with the highest molecular weight. ${ }^{3,34}$

Repeated administration of intra-articular hyaluronic acid is considered effective and safe. ${ }^{34}$

For information on the studies considered, see Appendix 3.

\section{Intra-Articular Injections - Corticosteroids Recommendation}

Intra-articular injections of corticosteroids are useful for short-term treatment of pain symptoms in patients with 
knee osteoarthritis. Particular attention should be paid to the potential damage caused by repeated use.

Statement elaborated on the basis of $\mathrm{RACGP}^{17}$ and $\mathrm{VA} / \mathrm{DoD}^{18}$ guidelines.

\section{Intra-Articular Injections - Platelet-Rich \\ Plasma \\ Recommendation}

At present, there is little reliable evidence on the use of intra-articular injections of platelet-rich plasma in the management of patients with knee osteoarthritis. No major safety problems have emerged up to now.

Statement elaborated on the basis of NICE-IPG637 guidelines. $^{28}$

\section{Slow-Acting Systemic Drugs - SYSADOAs \\ Glucosamine \\ Recommendation}

Glucosamine can be used for continuous treatment of the symptoms (pain and function) of knee osteoarthritis for at least 12 months. Data available in the literature suggest long-term efficacy of the prescription drug glucosamine sulfate but not for formulations containing other glucosamine salts.

\section{Comment}

There are several products containing glucosamine based on different chemical compositions.

Liu et $\mathrm{al}^{30}$ study the effects of glucosamine without considering the different formulations and the analyses conducted reveal slight but statistically significant effects on pain control in the short term (within 3 months), which do not maintain statistical significance in the medium term (up to 6 months) and are reduced further in the long term ( $>6$ months) reaching statistical significance. The effects on function are moderate and statistically significant in the short term, while the medium and long-term effects are not significant.

The meta-analysis conducted by Runhaar $^{31}$ considers the data shared by the authors involved, analysing the performance of the glucosamine products that do not require a prescription: the results for these formulations are not statistically significant for any outcome considered.

The study conducted by Gregori et $\mathrm{al}^{29}$ differentiates the long-term effects ( $\geq 12$ months) on pain, function and structure of the articulation between the various formulations: only glucosamine sulfate (specified as a prescription drug) is significantly associated with improvements in all parameters. Although these effects can be classified as slight, they were found to be superior to all the other treatments considered by the authors.

As far as adverse events are concerned, glucosamine can be considered a safe treatment. ${ }^{30}$

See Appendix 3 for information on the studies considered.

\section{Chondroitin}

\section{Recommendation}

Chondroitin can be considered for the treatment of symptoms (pain and function) in patients with knee osteoarthritis in the short term only (up to 6 months).

\section{Comment}

Also, for chondroitin there are formulations that require prescriptions and preparations sold over the counter.

Liu et $\mathrm{al}^{30}$ analyse the performance of chondroitin (without distinction between prescription forms and OTC forms), indicating limited but statistically significant improvements in pain and function in the short/medium term (up to 6 months), the long-term results do not reach statistical significance.

Also, the data obtained by Gregori ${ }^{29}$ on pain control and function in the long term ( $\geq 12$ months) are not statistically significant, while they are in association with the improvement of the articular structure, though less than the prescription drug glucosamine sulfate.

As far as the safety profile is concerned, treatment with chondroitin can be considered safe. ${ }^{30}$

See Appendix 3 for information on the studies considered.

\section{Avocado Soybean Unsaponifiables Recommendation}

The use of avocado soybean unsaponifiables is not supported by any scientific evidence.

Statement elaborated on the basis of RACGP ${ }^{17}$ and $\mathrm{OARSI}^{26}$ guidelines.

\section{Pharmacological Treatment}

\section{Oral Non-Steroidal Anti-Inflammatory Drugs (Including COX-2 Inhibitors) Recommendation}

The use of non-steroidal anti-inflammatory drugs (NSAIDs), including COX-2 inhibitors, can be considered 
for patients with knee osteoarthritis. The drug chosen should be administered at the lowest effective dose on pain and function for a limited period of time, considering the patient's comorbidities and monitoring any adverse gastrointestinal, hepatic, cardiovascular and renal effects.

Statement elaborated on the basis of RACGP, ${ }^{17}$ NICE$\mathrm{CG} 177^{27}$ and VA/DoD ${ }^{18}$ guidelines.

\section{Opioids}

\section{Recommendation}

The use of opioids can be considered for the treatment of pain in patients with knee osteoarthritis in which NSAIDs are ineffective or contraindicated, after balancing the riskbenefit profile of the patients.

Statement elaborated on the basis of RACGP $^{17}$ guidelines.

\section{Paracetamol}

Recommendation

Administration of paracetamol can be considered in patients with knee osteoarthritis, but only slight pain relief is obtained.

Statement elaborated on the basis of RACGP, ${ }^{17} \mathrm{VA} /$ $\mathrm{DoD}^{18}$ and $\mathrm{AAOS}^{25}$ guidelines.

\section{Topical Preparations}

\section{Recommendation}

The application of NSAIDs can be taken into consideration.

The use of other topical preparations is not recommended in patients with knee osteoarthritis due to the lack of scientific evidence.

Statement elaborated on the basis of $\mathrm{RACG}^{17}$ and $\mathrm{NICE}^{27}$ guidelines and indications from the work group.

\section{Comment}

The work group expressed a favourable opinion on the use of topical NSAIDs while, in agreement with the RACG and NICE guidelines, the use of other preparations containing capsaicin, rubefacients and opioids is not recommended.

\section{Walking Aids}

\section{Recommendation}

The use of walking aids (walking sticks, crutches, walking frames, etc.) may be appropriate for selected patients, taking into consideration also their individual comorbidities, preferences and capabilities. Patients must be taught how to use prescribed aids to ensure their efficacy and safety.

Statement elaborated on the basis of RACGP ${ }^{17}$ guidelines.

\section{Braces}

\section{Recommendation}

At present, there is little reliable evidence on the use of knee braces for the management of patients with knee osteoarthritis.

Statement elaborated on the basis of RACGP ${ }^{17}$ guidelines and indications from the experts.

\section{Foot Orthoses}

\section{Recommendation}

At present, there is little reliable evidence on the use of foot orthoses for the management of patients with knee osteoarthritis.

Statement elaborated on the basis of $\mathrm{RACGP}^{17}$ guidelines.

\section{Non-Substitutive Surgical Procedures \\ Arthroscopic Surgery \\ Recommendation}

Routine arthroscopic surgery (debridement, meniscectomy and cartilage repair techniques) is not recommended.

Arthroscopic surgery can be considered for treating the causes of mechanical articular blockage (e.g. Knee locking, acute injury, loose bodies), above all in patients unresponsive to conservative treatment and suffering from mild/moderate knee osteoarthritis.

Statement elaborated on the basis of RACGP, ${ }^{17} \mathrm{VA} /$ $\mathrm{DoD}^{18}$ and $\mathrm{AAOS}^{25}$ guidelines, In-depth analyses is by SIOT.

\section{Knee Realignment Osteotomy}

\section{Recommendation}

Knee realignment osteotomy (tibial/femoral) can be proposed for selected patients (eg active adults not overweight) with mild to moderate single-region symptomatic knee osteoarthritis.

Statement elaborated on the basis of $\mathrm{AAOS}^{25}$ guidelines and indications from the experts.

\section{Comment}

Characteristics of the patients selected:

- Alignment defect 
- Young adult (not elderly patients)

- Good/high functional requirement (active patient)

- Mild/moderate single-region knee osteoarthritis

- Patient of a normal weight

\section{Indications for Substitutive Surgery Recommendation}

Substitutive surgery should be taken into consideration for patients with severe symptoms and unresponsive to pharmacological and conservative treatments.

The most significant criteria to be considered for a knee prosthesis are:

- Joint pain with limited function

- Proven structural damage

- Failure of pharmacological/conservative treatments

- Deterioration in quality of life

- Significant subjective suffering

\section{Comment}

At present there are no standard criteria for establishing the eligibility of substitutive surgery for the treatment of knee osteoarthritis. The decision as to whether to subject the patient to surgery should be based on an assessment of the patient's clinical condition, their preferences and those of the surgeon. ${ }^{65}$

The summary papers and reviews ${ }^{64,65}$ considered in elaborating the recommendation propose the following criteria:

\section{Primary Criteria}

Joint Pain. The frequency and duration of the pain, together with a failure to respond to conservative treatments, are the most influential parameters. In particular, the pain symptom may last for at least 3-6 months. The pain may be continuous or intermittent with frequent episodes during the week.

The sources considered refer to moderate/severe pain without providing any specific assessment instruments or cut-offs.

Proven Structural Damage. Structural damage was established by an X-ray examination of the patient bearing his own weight. According to a document written by the British Orthopaedic Association, the X-ray must show severe knee osteoarthritis (Kellgren-Lawrence 3-4) in at least one compartment of the knee (quot. BOA).
Failure of Pharmacological/Conservative Treatments.

Patients should be given pharmacological conservative treatment and non-pharmacological conservative treatment for at least 3-6 months. Failure to respond to these combinations constitutes an indication of conservative surgery. Deterioration in Quality of Life. One of the criteria required for substitutive surgery is a significant deterioration in the quality of life that has lasted for at least 3-6 months. Significant Subjective Suffering. A major state of discomfort and suffering reported by the patient constitutes an indication for an operation.

\section{Secondary Criteria}

The secondary criteria are not necessary for the indication for substitutive surgery but their presence may influence the surgeon's decision.

- Limitations in walking (in terms of distance and duration) and in climbing steps

- Misalignment

- Articular instability

- Reduction of ROM

- Reduction of muscle strength

- Difficulty in sitting down, kneeling or personal hygiene

- Need for help from another person

- Difficulty in doing the housework

- Difficulty in using means of transport

- Restrictions in social life, work or sport

- Low risk of iatrogenic diseases

\section{Absolute Contraindications}

- Articular infection in progress

\section{Relative Contraindications}

- Extremely short life expectancy due to comorbidities

- High body mass index $(\geq 40)$

The conditions correlated to an increased risk of complications are:

- Previous infection of the articulation concerned

- Increased risk of infection

- Advanced peri-operative risk

- Physical comorbidities

- Psychological/psychiatric comorbidities 
- Treatments that increase the operative risk

- Substance dependence

- Neurological disorders

See Appendix 3 for information on the studies considered.

\section{Unapproved Recommendations Diacerein}

Diacerein can only be considered for short-term treatment ( $<3$ months) in patients with knee osteoarthritis who can tolerate it.

The panel formulated the recommendation but the quorum necessary for consensus was not reached.

\section{In-Depth Analyses}

During the discussion, the work group decided to provide detailed elements on some of the topics less well known and/or under development as research is being conducted on them.

\section{Therapeutic Exercise}

The purpose of therapeutic exercise is to restore correct movement in a functional setting through movement itself, which thus becomes the means and purpose of the physiotherapeutic proposal.

A classification of therapeutic exercise is based on the performance of the movement in relation to active muscle contraction. Three different conditions may arise. These conditions require three different types of exercise, according to the type of muscle contraction required:

1. Isometric exercise

2. Concentric exercise

3. Eccentric exercise

Therapeutic exercise is applied in sport rehabilitation, the sub-acute phases of post-surgical and post-traumatic rehabilitation, geriatric rehabilitation and all cases of functional recovery of the neuromusculoskeletal system.

\section{Muscle Contraction Terminology}

A muscle contraction that produces strength without a measurable modification of the joint angle is considered an isometric contraction. The isometric contraction is also called static or hold.
Resistance can be applied both manually and mechanically by instructing the patient to push against a fixed object or hold a heavy load.

An isotonic muscle contraction causes a joint to move across a range of motion (ROM). The resistance, both manual and mechanical, remains constant while the length of the muscle varies continuously.

There are two types of isotonic contraction.

- A concentric contraction shortens the muscle fibres.

The force generated by the muscle fibres is greater than the resistance encountered. A concentric contraction causes a body segment to accelerate. An example of concentric contraction of the quadriceps femoris is when the knee is stretched against slight resistance across the entire range of motion.

- An eccentric contraction is produced when the resistance encountered is greater than the force produced by the muscle fibres.

The muscle fibres stretch against the resistance. Eccentric contractions cause the body segment to decelerate and absorb the shock in many activities.

Nevertheless, eccentric contractions against high resistance could apply excessive stress to the cardiovascular system, so these contractions may be contraindicated in some patients.

Furthermore, the actual osteoarthromuscular structures may be subjected to an excessive overload.

An example of an eccentric contraction of the quadriceps in when you walk down stairs slowly.

An isokinetic contraction is a muscle contraction that takes place at a constant speed. As the speed of movement of the segment is constant, the resistance that the muscle fibres must encounter varies (called accommodating resistance). Isokinetic contractions can be exercised concentrically or eccentrically.

Various kinds of equipment are used to produce isokinetic contractions (isokinetic dynamometers).

This equipment can be used to program the speeds and develop maximal tension throughout the full range of motion.

Therapeutic exercise can be performed at a ratio of 1:1 between physiotherapist and patient or for small groups in which a physiotherapist supervises the performance of specific exercises in a group of 3-5 patients. 
In the advanced phases of a therapeutic program for any disabling pathological condition, the patient can be recommended to do a series of exercises autonomously (self-treatment) at home (called home program), with periodic check-ups by the rehabilitation team, if appropriate.

\section{Aerobic Exercises}

Physiologically, an aerobic exercise becomes such when the glycogen stores in the muscle are no longer sufficient to allow pyruvic acid to be converted back to ATP. For this reason, an exercise only starts to become aerobic when the effort is maintained for more than 3-4 minutes; a totally aerobic exercise is an effort that is maintained for about twenty minutes.

In the same time interval, less energy is used than in an anaerobic exercise, but as they are maintained for a longer time, more energy is used up.

On the contrary, an aerobic exercise, in scientific terms, is commonly called endurance or aerobic training, which means performing the exercise for a longer time.

The objectives on which a safe and effective aerobic training system should be based concern the following three principles:

- Frequency: The number of times the training is performed;

- Duration: The time for which the training lasts;

- Intensity: The strength, energy and difficulty of the training;

The body responds by increasing its capacity to withstand the effort, by adapting to the increase in physiological demand.

This creates a training effect (which must never give a burning sensation,; otherwise,an excessive amount of lactic acid is produced and this stimulates a continuous muscle contraction, with a constant delay of the training effect). ${ }^{38-42}$

\section{Chondroprotection and Magnetic Resonance Imaging in Knee Osteoarthritis}

Chondroprotection in knee osteoarthritis is a broad topic well known for over two decades, although its actual efficacy is the subject of considerable debate among osteoarticular system specialists.
The assessment of its use through magnetic resonance imaging is even more recent and was stimulated by a case report in 2003 by van Blitterswijk, ${ }^{68}$ in which an improvement in the imaging of the intervertebral discs of a patient with spondyloarthritis treated with glucosamine (GS) and chondroitin sulfate (CS) for two years.

The first randomized, placebo-controlled study (GS vs placebo/6 months) dates back to 2009 and was conducted by Marti-Bonmatì: ${ }^{67}$ this study involved 16 patients and showed an improvement in pain (VAS) and imaging (K trans in MRI). In 2011, Wildi et al ${ }^{68}$ enrolled 69 patients on a randomized double-blind, placebo-controlled study (CS $800 \mathrm{mg} /$ day vs placebo/6 months) and assessed bone oedema and cartilage volume at 6 and 12 months, revealing significant efficacy of the chondroprotection.

On the other hand, a more detailed randomized, double-blind, placebo-controlled study conducted by Railhac et al in $2012^{69}$ (43 patients, CS $1000 \mathrm{mg}$ /day vs placebo/ 1 year), revealed an improvement in pain on the VAS scale but no substantial changes to MRI, except for cartilage volume, the latter being an element that confirmed the previous study. The improvement in pain and the X-ray changes were the objective of the randomized, placebocontrolled study conducted by Durmus et $\mathrm{al}^{70}$ in 2012, in which 39 patients were divided into two groups: the first took GS $1500 \mathrm{mg} /$ day, the other, placebo for 12 weeks, but both were subjected to physiotherapeutic exercises. There were no appreciable differences between the cases and the controls with both groups reporting a reduction in pain and slower progression in MRI.

The randomized, placebo-controlled study conducted by Wilkens et $\mathrm{al}^{71}$ ( 45 patients, GS vs placebo/ 6 months) actually failed to demonstrate the efficacy of GS on Modic and hyperintense areas at the lumbar level in spondyloarthritis. Starting from 2013, longer observational studies began to appear in the literature. These studies included one by Raynauld et $\mathrm{al}^{72}$ (need for knee prosthesis 4 years after CS $800 \mathrm{mg} /$ day vs placebo/6 months). This study demonstrated a greater probability of needing a prosthesis in the group treated with placebo, also exposed to greater pain, high scores in the WOMAC questionnaire, presence of bone oedema and CRP level elevation.

Dubiously reproducible but, in any case, worthy of note is the study conducted by Jacobs et $\mathrm{al}^{73}$ on 18 rabbits subjected to GS for an equivalent dose in man of $1500 \mathrm{mg} /$ day, which surprisingly revealed a worsening of the conditions of the intervertebral discs in the group treated with 
GS. Kwoh et $\mathrm{al}^{74}$ in turn dampened the enthusiasm over the use of chondroprotectors: their randomized, placebocontrolled study of 2014 (201 patients, GS $1500 \mathrm{mg} / \mathrm{die}$ vs placebo/24 weeks) revealed no significant changes to the WORMS or urinary CTX, the secondary endpoint of the study.

Equally disappointing but, in a certain sense, in line with the study conducted by Durmus et $\mathrm{al}^{70}$ mentioned previously, was the study conducted by Armagan et $\mathrm{al}^{75}$ (2015, randomized, double-blind, placebo-controlled study) in which 70 patients were divided into one group taking $1500 \mathrm{mg} /$ day di GS and one subjected to physiotherapy. There was no appreciable difference between the two groups in the WOMAC questionnaire or on the VAS scale and the patients subjected to physiotherapy even presented less bone oedema.

Following the same model, in 2016, Landsmeer et al ${ }^{76}$ published a randomized, double-blind, placebo-controlled study in which 407 patients with BMI $>27$ were subjected to a diet, regimen of physical activity and GS or placebo. The MRI assessment using the MOAKS score revealed no significant differences between the two groups, apart from a reduction in meniscal extrusion.

Subsequently, Martel-Pelletier ${ }^{77}$ and Roubille ${ }^{78}$ published two studies, one randomized and the other longitudinal, on 600 patients, divided into GS and CS with or without the consumption of 2 NSAIDs for 2 years. The first documented a smaller loss of cartilage in patients receiving GS and CS combined with NSAIDs, while the second stratified these results better, documenting greater efficacy in patients with no meniscal extrusion.

For the same purpose, two other randomized, placebocontrolled studies conducted by the same authors assessed the superiority of CS $1200 \mathrm{mg} /$ day over celecoxib $200 \mathrm{mg} /$ day $/ 2$ years. In the first, published in $2016,{ }^{79}$ the primary endpoint, that is, the reduction of "cartilage volume loss" by GS was obtained, while there were no statistically significant differences in pain or oedema between the two groups. In the second study, published in $2017,{ }^{80}$ attention was centred on the inflammation and bone metabolism marker levels as predictors of response: the results showed that patients with low levels of ESR and CRP and high bone catabolism were the most likely to give a greater response to treatment with chondroprotectors. Finally, worthy of mention is the huge observational study conducted by Raynauld et $\mathrm{al}^{81}$ in which 1593 patients were subjected to the combination of GS and CS, with efficacy demonstrated by the structural changes visible in MRI.

\section{Vitamin D}

The association between serum vitamin $\mathrm{D}$ and knee osteoarthritis is a subject of much debate that is still topical, especially with regard to the therapeutic possibilities offered by cholecalciferol supplementation in the management of the most widespread rheumatic disease in Italy and the world.

In literature, the speculations on this topic are derived from an observational prospective study conducted by McAlindon et $\mathrm{al}^{43}$ which associated the serum levels of $25 \mathrm{OH}$ vit. D with the development of knee osteoarthritis. These results, but in a larger sample (237 women aged over 65 years), were confirmed again in 1999 by Lane et $\mathrm{al}^{44}$ who established a direct relationship between 1.25 and $25 \mathrm{OH}$ serum vit. D and hip arthritis.

In 2009, Bergink et $\mathrm{al}^{45}$ demonstrated the correlation between vit. D and knee osteoarthritis, through a largescale longitudinal study (1248 patients) that investigated the serum levels of $25 \mathrm{OH}$, their intake in the diet and the progression of the arthritis. The results of this study show a significant association between the diet intake of vitamin $\mathrm{D}$ and knee osteoarthritis, particularly in patients with low bone mineral density (BMD).

Also, a small but interesting in-vitro study conducted in 2017 by Huhtakangas et $\mathrm{a}^{46}$ shed new light on this correlation: using 8 knees with a prosthesis (4 patients with rheumatoid arthritis and 4 with knee osteoarthritis), it exposed the stromal cells to $1.25 \mathrm{OH}$ vit. D and calcipotriol, and found a reduction of the inflammation mediators in both groups, thus suggesting a role of vitamin D in slowing down the inflammatory processes. The case control study conducted by Brennan in $2017^{47}$ (19 patients with end-stage OA and 10 healthy patients), aiming to determine serum and muscle vit. D was also of great interest. Surprisingly, there were no appreciable differences in serum vit. D levels, but the vit. D binding proteins increased in the muscles of patients with arthritis. Subsequently, in the light of the aforesaid evidence, studies were conducted to find the possible therapeutic efficacy of the better known liposoluble vitamin in knee osteoarthritis multiplied.

In 2015, in a brief observational prospective study (67 patients), Heidari et $\mathrm{al}^{48}$ demonstrated that cholecalciferol $50,000 \mathrm{IU} / 14$ days $/ 2$ months increased the strength of the 
quadriceps and reduced pain in patients with knee osteoarthritis.

On the other hand, in 2013, McAlindon ${ }^{49}$ published the results of a randomized, placebo-controlled study (cholecalciferol $2000 \mathrm{IU} /$ day vs placebo for 2 years), which demonstrated no statistically significant differences between the two groups in reducing pain and in the radiological progression of the knee osteoarthritis.

This evidence was confirmed by Arden et $\mathrm{al}^{50}$ (2016, 474 patients, cholecalciferol $800 \mathrm{IU} / \mathrm{day} / 3$ years vs placebo) in their randomized, placebo-controlled study, in which vit. D supplementation failed to reduce both pain and radiological progression.

Also, Jin et $\mathrm{al}^{51}$ the first to use MRI in this field (tibial volume) were forced to underline the inefficacy of 50,000 IU of cholecalciferol/28 days/2 years in their randomized, prospective study, which was conducted on 413 patients and also used the WOMAC questionnaire.

In 2017, a systematic literature review conducted by Hussein et $\mathrm{a}^{52}$ investigated into the efficacy of variable doses of cholecalciferol in modifying VAS, WOMAC and Functional Pain Score (FPS) in patients with knee osteoarthritis, concluding that it was substantially ineffective.

Similar conclusions were reached by Gao et al ${ }^{53}$ (metaanalysis of 4 RCTs, 2017), who, in a total of 1136 patients failed to find a significant reduction in stiffness and cartilage damage. Nevertheless, this meta-analysis showed statistically significant differences in pain relief and function in the WOMAC questionnaire.

Finally, in 2019, the randomized, placebo-controlled study by Perry et $\mathrm{al}^{54}$ (50 patients, cholecalciferol 800 IU/day vs placebo), which measured the synovial volume and bone oedema in the two groups of study, found no significant differences between patients treated with vitamin D and those treated with a placebo.

\section{Intra-Articular Hyaluronic Acid- Molecular Weight}

The efficacy of HA products varies according to their origin, method of production, molecular weight (MW), viscoelasticity, rheological properties, half-life in the articulation, pharmacokinetics and pharmacodynamics, and the number of injections in each treatment cycle. In general, the half-life of HA products in the articulation is just a few days and thus much shorter than the duration of the clinical effect. The clinical trials provide no proof of the superiority of a single brand of hyaluronic acid product over others. In general, patients with a normal weight and those with less severe OA respond better to HA viscosupplementation. With regard to the differences in MW and degree of cross-linking, three Meta-analyses have reported better results with high-molecular-weight products than with low-molecular-weight products. ${ }^{26,81,82}$

This tendency towards an increase in efficacy with increases in MW was also reported in the AAOS15 guidelines and in a previous MA conducted by Bannuru et $\mathrm{al}^{83}$ showing a considerable difference in Effect Size in terms of pain in favour of the higher MW $(\geqslant 6000 \mathrm{kDA}, \mathrm{SE} 0.60$, CI 95\% 0.33-0.88) compared to a lower MW $(<1000 \mathrm{kDa}$, SE 0.29, CI 95\% 0.14-0.44). Nevertheless, the optimum MW cut-off has not yet been established and more extensive comparative studies are necessary to confirm this superiority and determine the precise cut-off.

\section{Brace in a Small Group of Asymptomatic Patients with Patellofemoral Instability and Valgus Instability}

In 2007, a new valgus brace was assessed by Gaasbeek et al. ${ }^{84}$ In 15 patients with medial OA of the knee and a varus axis. A significant improvement of the pain and functional scores was observed after 6 weeks. A gait analysis showed that the brace tended to reduce the varus moment on the knee. This effect was more preponderant in the presence of a larger initial varus angle.

In 2015 , Mont et al ${ }^{85}$ conducted a randomized prospective study on 18 patients with Kellgren-Lawrence grades 1 and 2. The use of an unloader brace showed similar improvements to standard treatments for knee OA.

In 2016, Yu et al ${ }^{86}$ analysed 204 participants; concluding that wearing a patellofemoral brace or a tibiofemoral brace does not seem to bring any further improvements.

Steadman et $\mathrm{al}^{87}$ recently reviewed the biomechanical impact of the brace on the mechanics of the knee, concluding that despite there being an improvement in pain and function, the unloading of the knee compartment failed to significantly obstruct the progression of OA.

The study conducted by Ostrander et al ${ }^{88}$ demonstrated that the use of an unloader brace for the medial compartment improves pain relief.

In patients with end-stage OA, encouraging results were obtained from the use of a pneumatic brace with assisted stretching. Kapadia et $\mathrm{al}^{89}$ state that this device represents a promising treatment option for knee OA, capable of improving gait, pain relief and strength. 
In 2016, Petersen et $\mathrm{al}^{90}$ included 24 articles in a systematic review of the mechanical effect of unloader knee braces. Twenty demonstrated that these braces significantly reduce the knee adduction moment. Seven of these studies found a reduction in the patients' pain and four failed to reveal any effect on the knee adduction moment.

In 2010, Fantini Pagani et al ${ }^{91}$ analysed patients with a valgus brace while walking and running. The orthosis tested was effective in reducing the adduction of the knee in walking and running. This reduction in knee adduction should help to slow down the progression of OA.

In 2014 Haladik et $\mathrm{al}^{92}$ analysed 100 patients with arthritis in the medial compartment treated with a knee unloader brace. The patients had a dynamic X-ray in two projections while walking with and without the brace. The data obtained in this study suggested that the brace was ineffective in reducing the adduction movement of the knee but that it was effective in improving pain relief.

As far as patellofemoral arthritis is concerned, Yu et $\mathrm{al}^{86}$ reported that wearing a patellofemoral brace does not seem to provide any further benefits in patients with OA.

In a systematic review of arthritis in the medial compartment of the knee, Duivenvoorden et al demonstrated that it has a beneficial effect in terms of pain relief, function and quality of life. Another systematic review conducted by Petersen et $\mathrm{al}^{90}$ and other states that the unloader brace reduces the knee adduction moment.

\section{In-Depth Analysis Conducted by SIOT on Arthroscopic Procedures}

Some recent RCTs have shown that an arthroscopic wash, with or without a meniscectomy, has an efficacy against knee osteoarthritis comparable to a placebo and is therefore still an extremely overused procedure. ${ }^{55}$ If the remote possibility of adverse effects of the procedure ${ }^{56}$ is also considered, it would be reasonable to assume that arthroscopic wash of the arthritic knee should be completely abandoned, as sustained in some authoritative editorials. ${ }^{57,58}$

Nevertheless, in the setting of degenerative knee osteoarthritis, other variables may suggest that an arthroscopy could be useful, in particular, if conservative treatment fails and mechanical symptoms are present: ${ }^{59,60}$ a meniscal disease arising acutely after an injury, the presence of loose bodies and articular blockage represents potential indications for arthroscopic surgery also in the presence of knee osteoarthritis, particularly if moderate. $^{61,62}$

It is therefore believed to be fundamentally important to make a careful selection of the patients who, on the basis of their medical history, clinical and instrumental examination and after an adequate assessment of their expectations, could obtain a reasonable benefit from the arthroscopic treatment, while systematic use of the procedure should be discouraged.

\section{Acknowledgments}

The methodological and logistical support was provided by AdRes and CDPharma, who examined and summarized the existing literature, handled the systematic searches requested by the panel and the communications with the specialists. The document was drawn up with the unconditional contribution of Mylan.

\section{Panel}

Checchia, Giovanni Antonio - Department of Physical Medicine and Rehabilitation of the "Madre Teresa di Calcutta" Hospital of Monselice, Padua

Franceschi, Francesco - Upper and Lower Limb Surgery Unit of the Biomedical Campus University Hospital of Rome

Frediani, Bruno - Rheumatology Unit of the "Santa Maria alle Scotte" Hospital of Siena

Iannone, Florenzo - Rheumatology Unit, Department and Organ Transplantation Rheumatology Unit of the Aldo Moro University of Bari

Romanini, Emilio - Polo Sanitario San Feliciano, Rome

\section{Contributors}

SIMFER: Andreoli Ernesto, Arioli Giovanni, Bernetti Andrea, Brotto Andrea, Coco Valeria, Fiore Pietro, Gaeta Raffaella, Mazzon Stefano, Pasquetti Pietro, Polimeni Vincenzo, Sanna Cristina, Rusca Lia.

SIOT: Boniforti Filippo, Conte Marco, Galasso Olimpio, Magaletti Massimiliano, Maione Alessio, Moretti Biagio, Padua Roberto, Russo Arcangelo, Simonetta Roberto, Tornago Stefano, Tucci Gabriele, Zanoli Gustavo. 
SIR: Fioravanti Antonella, Guiducci Serena, Matucci Cerinic Marco, Migliore Alberto, Muratore Maurizio, Quartuccio Luca, Ramonda Roberta, Rossini Maurizio, Santo Leonardo, Todoerti Monica, Varcasia Giuseppe. SIOMMMS: Falchetti Alberto, Migliaccio Silvia.

\section{Disclosure}

G.A. Checchia has received consultancy fees and/or speaker honoraria from AlfaSigma AlfaWasserman outside this work; F. Franceschi declares no conflict of interest; L. Pradelli and T. Sinigaglia are employees of AdRes, which has been contracted by CDPharma, using an unconditional grant by Mylan for this work, and funding form many pharmaceutical and medical device companies outside this work; B. Frediani declares no conflict of interest; F. Iannone has received consultancy fees and/or speaker honoraria from Pfizer, AbbVie, MSD, BMS, Lilly, Novartis, Sanofi, Celgene, UCB outside this work; E. Romanini declares no conflict of interest. The authors report no other conflicts of interest in this work.

\section{References}

1. Moskowitz RW, Howell DS, Altman RD, Buckwalter JA, Goldberg VM. Osteoarthritis: Diagnosis and Medical/Surgical Management. 3rd ed. 2001:69-99.

2. Piscitelli P, Iolascon G, Di Tanna G, et al. Socioeconomic burden of total joint arthroplasty for symptomatic hip and knee osteoarthritis in the Italian population: a 5-year analysis based on hospitalization records. Arthritis Care Res. 2012;64(9):1320-1327. doi:10.1002/acr.21706

3. Michelle H. Physical Agents in Rehabilitation. An Evidence-Based Approach to Practice. 5th ed. Canada: Elsevier; 2008.

4. Santilli V. Linee guida ed evidenze scientifiche in medicina fisica e riabilitativa, Roma. Centro Stampa Università di Roma "La Sapienza"; 2018:1-736. Available from: http://www.formazionesostenibile.it/2017/ RomeRehabilitation/libro_per_sito.pdf. Accessed April 8,2021.

5. Zeng C, Li H, Yang T, et al. Electrical stimulation for pain relief in knee osteoarthritis: systematic review and network meta-analysis. Osteoarthr Cartil. 2015;23(2):189-202. doi:10.1016/j. joca.2014.11.014

6. Wang $\mathrm{H}$, Zhang $\mathrm{C}$, Gao C, et al. Effects of short-wave therapy in patients with knee osteoarthritis: a systematic review and meta-analysis. Clin Rehabil. 2017;31(5):660-671. doi:10.1177/ 0269215516683000

7. Giggins O, Fullen B, Coughlan G. Neuromuscular electrical stimulation in the treatment of knee osteoarthritis: a systematic review and meta-analysis. Clin Rehabil. 2012;26(10):867-881. doi:10.1177/ 0269215511431902

8. Benedetti MG, Boccia G, Cavazzuti L, et al. Localized muscle vibration reverses quadriceps muscle hypotrophy and improves physical function: a clinical and electrophysiological study. Int J Rehabil Res. 2017;40(4):339-346. doi:10.1097/mrr.0000000000000242

9. Rayegani SM, Raeissadat SA, Heidari S, Moradi-Joo M. Safety and effectiveness of low-level laser therapy in patients with knee osteoarthritis: a systematic review and meta-analysis. J Lasers Med Sci. 2017;8(Suppl 1):S12-s19. doi:10.15171/jlms.2017.s3
10. Li S, Yu B, Zhou D, He C, Zhuo Q, Hulme JM. Electromagnetic fields for treating osteoarthritis. Cochrane Database Syst Rev. 2013;12:Cd003523. doi:10.1002/14651858.CD003523.pub2

11. Ryang We S, Koog YH, Jeong KI, Wi H. Effects of pulsed electromagnetic field on knee osteoarthritis: a systematic review. Rheumatology. 2013;52(5):815-824. doi:10.1093/rheumatology/kes063

12. Alayat MSM, Aly THA, Elsayed AEM, Fadil ASM. Efficacy of pulsed Nd:YAG laser in the treatment of patients with knee osteoarthritis: a randomized controlled trial. Lasers Med Sci. 2017;32 (3):503-511. doi:10.1007/s10103-017-2141-x

13. Rutjes AW, Nüesch E, Sterchi R, et al. Transcutaneous electrostimulation for osteoarthritis of the knee. Cochrane Database Syst Rev. 2009;2009(4):Cd002823. doi:10.1002/14651858.CD002823. pub2

14. Rutjes AW, Nüesch E, Sterchi R, Jüni P. Therapeutic ultrasound for osteoarthritis of the knee or hip. Cochrane Database Syst Rev. 2010;1:Cd003132. doi:10.1002/14651858.CD003132.pub2

15. Zhang C, Xie Y, Luo X, et al. Effects of therapeutic ultrasound on pain, physical functions and safety outcomes in patients with knee osteoarthritis: a systematic review and meta-analysis. Clin Rehabil. 2016;30(10):960-971. doi:10.1177/0269215515609415

16. National Cancer Institute. Dictionary of cancer terms. Available from: https://www.cancer.gov/publications/dictionaries/cancer-terms /def/mind-body-exercise. Accessed April 7, 2021.

17. The Royal Australian College of General Practitioners. Guideline for the Management of Knee and Hip Osteoarthritis. 2nd. East Melbourne, Vic: RACGP; 2018:1-71. Available from: https://www. racgp.org.au/download/Documents/Guidelines/Musculoskeletal/guide line-for-the-management-of-knee-and-hip-oa-2nd-edition.pdf. Accessed April 8, 2021.

18. Department of Veterans Affairs Department of Defense. VA/DoD clinical practice guideline for the non-surgical management of hip \& knee osteoarthritis. Version 1.0; 2014:1-126. Available from: https://www.healthquality.va.gov/guidelines/CD/OA/ VADoDOACPGFINAL090214.pdf. Accessed April 8, 2021.

19. Forestier R, Desfour H, Tessier JM, et al. Spa therapy in the treatment of knee osteoarthritis: a large randomised multicentre trial. Ann Rheum Dis. 2010;69(4):660-665. doi:10.1136/ ard.2009.113209

20. Antonelli M, Donelli D, Fioravanti A. Effects of balneotherapy and spa therapy on quality of life of patients with knee osteoarthritis: a systematic review and meta-analysis. Rheumatol Int. 2018;38 (10):1807-1824. doi:10.1007/s00296-018-4081-6

21. Fioravanti A, Karagülle M, Bender T, Karagülle MZ. Balneotherapy in osteoarthritis: facts, fiction and gaps in knowledge. Eur J Integr Med. 2017;9:148-150. doi:10.1016/j.eujim.2017.01.001

22. Forestier R, Erol forestier FB, Francon A. Spa therapy and knee osteoarthritis: a systematic review. Ann Phys Rehabil Med. 2016;59 (3):216-226. doi:10.1016/j.rehab.2016.01.010

23. Matsumoto H, Hagino H, Hayashi K, et al. The effect of balneotherapy on pain relief, stiffness, and physical function in patients with osteoarthritis of the knee: a meta-analysis. Clin Rheumatol. 2017;36 (8):1839-1847. doi:10.1007/s10067-017-3592-y

24. Fraioli A, Mennuni G, Fontana M, et al. Efficacy of spa therapy, mud-pack therapy, balneotherapy, and mud-bath therapy in the management of knee osteoarthritis. a systematic review. Biomed Res Int. 2018;2018:1042576. doi:10.1155/2018/1042576

25. Jevsevar DS. Treatment of osteoarthritis of the knee: evidence-based guideline, 2nd edition. J Am Acad Orthop Surg. 2013;21(9):571-576. doi:10.5435/jaaos-21-09-571

26. McAlindon TE, Bannuru RR, Sullivan MC, et al. OARSI guidelines for the non-surgical management of knee osteoarthritis. Osteoarthr Cartil. 2014;22(3):363-388. doi:10.1016/j. joca.2014.01.003 
27. National Clinical Guideline C. National institute for health and clinical excellence: guidance. Osteoarthritis: care and management in adults. National Institute for Health and Care Excellence (UK).

28. National Institute for Health and Care Excellence. Platelet-rich plasma injections for knee osteoarthritis. Interventional procedures guidance [IPG637]; 2019:1-4. Available from: https://www.nice.org. uk/guidance/ipg637. Accessed April 8, 2021.

29. Gregori D, Giacovelli G, Minto C, et al. Association of pharmacological treatments with long-term pain control in patients with knee osteoarthritis: a systematic review and meta-analysis. JAMA. 2018;320(24):2564-2579. doi:10.1001/jama.2018.19319

30. Liu X, Machado GC, Eyles JP, Ravi V, Hunter DJ. Dietary supplements for treating osteoarthritis: a systematic review and meta-analysis. Br J Sports Med. 2018;52(3):167-175. doi:10.1136/ bjsports-2016-097333

31. Runhaar J, Rozendaal RM, van Middelkoop M, et al. Subgroup analyses of the effectiveness of oral glucosamine for knee and hip osteoarthritis: a systematic review and individual patient data meta-analysis from the OA trial bank. Ann Rheum Dis. 2017;76 (11):1862-1869. doi:10.1136/annrheumdis-2017-211149

32. Bhandari M, Bannuru RR, Babins EM, et al. Intra-articular hyaluronic acid in the treatment of knee osteoarthritis: a Canadian evidence-based perspective. Ther Adv Musculoskelet Dis. 2017;9 (9):231-246. doi:10.1177/1759720x17729641

33. Vannabouathong C, Bhandari M, Bedi A, et al. Nonoperative treatments for knee osteoarthritis: an evaluation of treatment characteristics and the intra-articular placebo effect: a systematic review. JBJS Rev. 2018;6(7):e5. doi:10.2106/jbjs.Rvw.17.00167

34. Altman R, Hackel J, Niazi F, Shaw P, Nicholls M. Efficacy and safety of repeated courses of hyaluronic acid injections for knee osteoarthritis: a systematic review. Semin Arthritis Rheum. 2018;48 (2):168-175. doi:10.1016/j.semarthrit.2018.01.009

35. Brosseau L, Taki J, Desjardins B, et al. The Ottawa panel clinical practice guidelines for the management of knee osteoarthritis. Part one: introduction, and mind-body exercise programs. Clin Rehabil. 2017;31(5):582-595. doi:10.1177/0269215517691083

36. Brosseau L, Taki J, Desjardins B, et al. The Ottawa panel clinical practice guidelines for the management of knee osteoarthritis. Part two: strengthening exercise programs. Clin Rehabil. 2017;31 (5):596-611. doi:10.1177/0269215517691084

37. Brosseau L, Taki J, Desjardins B, et al. The Ottawa panel clinical practice guidelines for the management of knee osteoarthritis. Part three: aerobic exercise programs. Clin Rehabil. 2017;31(5):612-624. doi:10.1177/0269215517691085

38. American Academy of Orthopaedic Surgeons. Athletic Training and Sports Medicine. 2nd ed. Park Ridge, Ill: American Academy of Orthopaedic Surgery; 1991.

39. Beckham-Burnett S, Grang WA. Safe and effective weight training for fitness and sport. J Musculoskelet Med. 1987;4(11):26-36.

40. Brotzman SB, Wilk KE. La Riabilitazione in Ortopedia. 2nd ed. San Donato Milanese: MI: Excerpta Medica Italia Srl; 2004.

41. Kisner C, Colby LA. Therapeutic exercise: foundations and techniques. Philadelphia: F.A. Davis; 1996:1-991. Availablefrom: https://www.academia.edu/43265538/Colby_Lynn_Allen_Kisner_ Carolyn_Therapeutic_exercise_Foundations_and_techniques_F_A_ Davis. Accessed April 8, 2021.

42. Richards DB, Kibler B. Sports-related rehabilitation: an overview of concepts. J Musculoskelet Med. 1997;14(8):44-63.

43. McAlindon TE, Felson DT, Zhang Y, et al. Relation of dietary intake and serum levels of vitamin D to progression of osteoarthritis of the knee among participants in the Framingham study. Ann Intern Med. 1996;125(5):353-359. doi:10.7326/0003-4819-125-5-19960901000001
44. Lane NE, Gore LR, Cummings SR, et al. Serum vitamin D levels and incident changes of radiographic hip osteoarthritis: a longitudinal study. Study of osteoporotic fractures research group. Arthritis Rheum. 1999;42 (5):854-860. doi:10.1002/1529-0131(199905)42:5<854::aid-anr3>3.0. Co;2-i

45. Bergink AP, Uitterlinden AG, Van Leeuwen JP, et al. Vitamin D status, bone mineral density, and the development of radiographic osteoarthritis of the knee: the Rotterdam study. J Clin Rheumatol. 2009;15(5):230-237. doi:10.1097/RHU.0b013e3181b08f20

46. Huhtakangas JA, Veijola J, Turunen S, et al. Cytokine data obtained from synovial stromal cells of patients with rheumatoid arthritis or osteoarthritis. Data Brief. 2017;12:593-602. doi:10.1016/j.dib.2017.04.041

47. Brennan-Speranza TC, Mor D, Mason RS, et al. Skeletal muscle vitamin $\mathrm{D}$ in patients with end stage osteoarthritis of the knee. J Steroid Biochem Mol Biol. 2017;173:180-184. doi:10.1016/j.jsbmb.2017.01.022

48. Heidari B, Javadian Y, Babaei M, Yousef-Ghahari B. Restorative effect of vitamin D deficiency on knee pain and quadriceps muscle strength in knee osteoarthritis. Acta Med Iran. 2015;53(8):466-470.

49. McAlindon T, LaValley M, Schneider E, et al. Effect of vitamin D supplementation on progression of knee pain and cartilage volume loss in patients with symptomatic osteoarthritis: a randomized controlled trial. JAMA. 2013;309(2):155-162. doi:10.1001/jama.2012.164487

50. Arden NK, Cro S, Sheard S, et al. The effect of vitamin D supplementation on knee osteoarthritis, the VIDEO study: a randomised controlled trial. Osteoarthr Cartil. 2016;24 (11):1858-1866. doi:10.1016/j.joca.2016.05.020

51. Jin X, Jones G, Cicuttini F, et al. Effect of vitamin D supplementation on tibial cartilage volume and knee pain among patients with symptomatic knee osteoarthritis: a randomized clinical trial. JAMA. 2016;315(10):1005-1013. doi:10.1001/jama.2016.1961

52. Hussain S, Singh A, Akhtar M, Najmi AK. Vitamin D supplementation for the management of knee osteoarthritis: a systematic review of randomized controlled trials. Rheumatol Int. 2017;37(9):1489-1498. doi:10.1007/s00296-017-3719-0

53. Gao XR, Chen YS, Deng W. The effect of vitamin D supplementation on knee osteoarthritis: a meta-analysis of randomized controlled trials. Int J Surg. 2017;46:14-20. doi:10.1016/j.ijsu.2017.08.010

54. Perry TA, Parkes MJ, Hodgson R, Felson DT, O'Neill TW, Arden NK. Effect of vitamin D supplementation on synovial tissue volume and subchondral bone marrow lesion volume in symptomatic knee osteoarthritis. BMC Musculoskelet Disord. 2019;20(1):76. doi:10.1186/s12891-019-2424-4

55. Thorlund JB, Juhl CB, Roos EM, Lohmander LS. Arthroscopic surgery for degenerative knee: systematic review and meta-analysis of benefits and harms. BMJ. 2015;350:h2747. doi:10.1136/bmj.h2747

56. Abram SGF, Judge A, Beard DJ, Price AJ. Adverse outcomes after arthroscopic partial meniscectomy: a study of 700000 procedures in the national hospital episode statistics database for England. Lancet. 2018;392(10160):2194-2202. doi:10.1016/s0140-6736(18)31771-9

57. Carr A. Arthroscopic surgery for degenerative knee. BMJ. 2015;350: h2983. doi:10.1136/bmj.h2983

58. Lohmander LS, Thorlund JB, Roos EM. Routine knee arthroscopic surgery for the painful knee in middle-aged and old patients-time to abandon ship. Acta orthopaedica. 2016;87(1):2-4. doi:10.3109/ 17453674.2015.1124316

59. Beaufils P, Becker R, Kopf S, et al. Surgical management of degenerative meniscus lesions: the 2016 ESSKA meniscus consensus. Knee Surg Sports Traumatol Arthrosc. 2017;25(2):335-346. doi:10.1007/ s00167-016-4407-4

60. Buldu MT, Marsh JL, Arbuthnot J. Mechanical symptoms of osteoarthritis in the knee and arthroscopy. J Knee Surg. 2016;29(5):396-402. doi:10.1055/s-0035-1564592

61. Lamplot JD, Brophy RH. The role for arthroscopic partial meniscectomy in knees with degenerative changes: a systematic review. Bone Joint J. 2016;98-b(7):934-938. doi:10.1302/0301-620x.98b7.37410 
62. Khan M, Khanna V, Adili A, Ayeni OR, Bedi A, Bhandari M. Knee osteoarthritis: when arthroscopy can help. Pol Arch Intern Med. 2018;128(2):121-125. doi:10.20452/pamw.4186

63. Price AJ, Alvand A, Troelsen A, et al. Knee replacement. Lancet. 2018;392(10158):1672-1682. doi:10.1016/s0140-6736(18)32344-4

64. Schmitt J, Lange T, Günther KP, et al. Indication criteria for total knee arthroplasty in patients with osteoarthritis - a multi-perspective consensus study. $Z$ Orthop Unfall. 2017;155(5):539-548. doi: $10.1055 / \mathrm{s}-0043-115120$

65. Gademan MG, Hofstede SN, Vliet Vlieland TP, Nelissen RG, Marang-van de Mheen PJ. Indication criteria for total hip or knee arthroplasty in osteoarthritis: a state-of-the-science overview. BMC Musculoskelet Disord. 2016;17(1):463. doi:10.1186/s12891-016-1325-z

66. van Blitterswijk WJ, van de Nes JC, Wuisman PI. Glucosamine and chondroitin sulfate supplementation to treat symptomatic disc degeneration: biochemical rationale and case report. BMC Complement Altern Med. 2003;3:2. doi:10.1186/1472-6882-3-2

67. Martí-Bonmatí L, Sanz-Requena R, Rodrigo JL, Alberich-Bayarri A, Carot JM. Glucosamine sulfate effect on the degenerated patellar cartilage: preliminary findings by pharmacokinetic magnetic resonance modeling. Eur Radiol. 2009;19(6):1512-1518. doi:10.1007/ s00330-008-1286-1

68. Wildi LM, Raynauld JP, Martel-Pelletier J, et al. Chondroitin sulphate reduces both cartilage volume loss and bone marrow lesions in knee osteoarthritis patients starting as early as 6 months after initiation of therapy: a randomised, double-blind, placebo-controlled pilot study using MRI. Ann Rheum Dis. 2011;70(6):982-989. doi:10.1136/ ard.2010.140848

69. Railhac JJ, Zaim M, Saurel AS, Vial J, Fournie B. Effect of 12 months treatment with chondroitin sulfate on cartilage volume in knee osteoarthritis patients: a randomized, double-blind, placebo-controlled pilot study using MRI. Clin Rheumatol. 2012;31 (9):1347-1357. doi:10.1007/s10067-012-2022-4

70. Durmus D, Alayli G, Bayrak IK, Canturk F. Assessment of the effect of glucosamine sulfate and exercise on knee cartilage using magnetic resonance imaging in patients with knee osteoarthritis: a randomized controlled clinical trial. J Back Musculoskelet Rehabil. 2012;25 (4):275-284. doi:10.3233/bmr-2012-0336

71. Wilkens P, Storheim K, Scheel I, Berg L, Espeland A. No effect of 6-month intake of glucosamine sulfate on Modic changes or high intensity zones in the lumbar spine: sub-group analysis of a randomized controlled trial. J Negat Results Biomed. 2012;11:13. doi:10.1186/1477-5751-11-13

72. Raynauld JP, Martel-Pelletier J, Dorais M, et al. Total knee replacement as a knee osteoarthritis outcome: predictors derived from a 4-year long-term observation following a randomized clinical trial using chondroitin sulfate. Cartilage. 2013;4(3):219-226. doi:10.1177/1947603513483547

73. Jacobs L, Vo N, Coelho JP, et al. Glucosamine supplementation demonstrates a negative effect on intervertebral disc matrix in an animal model of disc degeneration. Spine. 2013;38(12):984-990. doi:10.1097/BRS.0b013e318286b31e

74. Kwoh CK, Roemer FW, Hannon MJ, et al. Effect of oral glucosamine on joint structure in individuals with chronic knee pain: a randomized, placebo-controlled clinical trial. Arthritis Rheum. 2014;66(4):930-939. doi:10.1002/art.38314

75. Armagan O, Yilmazer S, Calısir C, et al. Comparison of the symptomatic and chondroprotective effects of glucosamine sulphate and exercise treatments in patients with knee osteoarthritis. J Back Musculoskelet Rehabil. 2015;28(2):287-293. doi:10.3233/bmr-140516

76. Landsmeer ML, Runhaar J, van der Plas P, et al. Reducing progression of knee OA features assessed by MRI in overweight and obese women: secondary outcomes of a preventive RCT. Osteoarthr Cartil. 2016;24(6):982-990. doi:10.1016/j. joca.2015.12.016
77. Martel-Pelletier J, Roubille C, Abram F, et al. First-line analysis of the effects of treatment on progression of structural changes in knee osteoarthritis over 24 months: data from the osteoarthritis initiative progression cohort. Ann Rheum Dis. 2015;74(3):547-556. doi:10.1136/annrheumdis-2013-203906

78. Roubille C, Martel-Pelletier J, Abram F, et al. Impact of disease treatments on the progression of knee osteoarthritis structural changes related to meniscal extrusion: data from the OAI progression cohort. Semin Arthritis Rheum. 2015;45(3):257-267. doi:10.1016/j. semarthrit.2015.05.001

79. Pelletier JP, Raynauld JP, Beaulieu AD, et al. Chondroitin sulfate efficacy versus celecoxib on knee osteoarthritis structural changes using magnetic resonance imaging: a 2-year multicentre exploratory study. Arthritis Res Ther. 2016;18(1):256. doi:10.1186/s13075-016-1149-0

80. Martel-Pelletier J, Raynauld JP, Mineau F, et al. Levels of serum biomarkers from a two-year multicentre trial are associated with treatment response on knee osteoarthritis cartilage loss as assessed by magnetic resonance imaging: an exploratory study. Arthritis Res Ther. 2017;19(1):169. doi:10.1186/s13075-017-1377-y

81. Raynauld JP, Pelletier JP, Abram F, Dodin P, Delorme P, MartelPelletier J. Long-term effects of glucosamine and chondroitin sulfate on the progression of structural changes in knee osteoarthritis: six-year followup data from the osteoarthritis initiative. Arthritis Care Res. 2016;68(10):1560-1566. doi:10.1002/acr.22866

82. Altman RD, Bedi A, Karlsson J, Sancheti P, Schemitsch E. Product differences in intra-articular hyaluronic acids for osteoarthritis of the knee. Am J Sports Med. 2016;44(8):2158-2165. doi:10.1177/ 0363546515609599

83. Bannuru RR, Natov NS, Dasi UR, Schmid CH, McAlindon TE. Therapeutic trajectory following intra-articular hyaluronic acid injection in knee osteoarthritis-meta-analysis. Osteoarthr Cartil. 2011;19 (6):611-619. doi:10.1016/j.joca.2010.09.014

84. Gaasbeek RD, Groen BE, Hampsink B, van Heerwaarden RJ, Duysens J. Valgus bracing in patients with medial compartment osteoarthritis of the knee. A gait analysis study of a new brace. Gait Posture. 2007;26(1):3-10. doi:10.1016/j.gaitpost.2006.07.007

85. Mont MA, Cherian JJ, Bhave A, et al. Unloader bracing for knee osteoarthritis: a pilot study of gait and function. Surg Technol Int. 2015;27:287-293.

86. Yu SP, Williams M, Eyles JP, Chen JS, Makovey J, Hunter DJ. Effectiveness of knee bracing in osteoarthritis: pragmatic trial in a multidisciplinary clinic. Int $J$ Rheum Dis. 2016;19(3):279-286. doi:10.1111/1756-185x.12796

87. Steadman JR, Briggs KK, Pomeroy SM, Wijdicks CA. Current state of unloading braces for knee osteoarthritis. Knee Surg Sports Traumatol Arthrosc. 2016;24(1):42-50. doi:10.1007/s00167-014-3305-x

88. Ostrander RV, Leddon CE, Hackel JG, O'Grady CP, Roth CA. Efficacy of unloader bracing in reducing symptoms of knee osteoarthritis. Am J Orthop. 2016;45(5):306-311.

89. Kapadia BH, Cherian JJ, Starr R, et al. Gait using pneumatic brace for end-stage knee osteoarthritis. J Knee Surg. 2016;29(3):218-223. doi:10.1055/s-0036-1579790

90. Petersen W, Ellermann A, Zantop T, et al. Biomechanical effect of unloader braces for medial osteoarthritis of the knee: a systematic review (CRD 42015026136). Arch Orthop Trauma Surg. 2016;136 (5):649-656. doi:10.1007/s00402-015-2388-2

91. Fantini Pagani CH, Potthast W, Bruggemann GP. The effect of valgus bracing on the knee adduction moment during gait and running in male subjects with varus alignment. Clin Biomech. 2010;25 (1):70-76. doi:10.1016/j.clinbiomech.2009.08.010

92. Haladik JA, Vasileff WK, Peltz CD, Lock TR, Bey MJ. Bracing improves clinical outcomes but does not affect the medial knee joint space in osteoarthritic patients during gait. Knee Surg Sports Traumatol Arthrosc. 2014;22(11):2715-2720. doi:10.1007/s00167013-2596-7 
93. Duivenvoorden T, Brouwer RW, van Raaij TM, Verhagen AP, Verhaar JA, Bierma-Zeinstra SM. Braces and orthoses for treating osteoarthritis of the knee. Cochrane Database Syst Rev. 2015;3: Cd004020. doi:10.1002/14651858.CD004020.pub3

94. Hochberg MC, Altman RD, April KT, et al. American college of rheumatology 2012 recommendations for the use of nonpharmacologic and pharmacologic therapies in osteoarthritis of the hand, hip, and knee. Arthritis Care Res. 2012;64(4):465-474. doi:10.1002/acr.21596

95. Nussbaum EL, Houghton P, Anthony J, Rennie S, Shay BL, Hoens AM. Neuromuscular electrical stimulation for treatment of muscle impairment: critical review and recommendations for clinical practice. Physiother Can. 2017;69(5):1-76. doi:10.3138/ptc.2015-88
96. Bruyère $\mathrm{O}$, Cooper $\mathrm{C}$, Pelletier JP, et al. A consensus statement on the European Society for Clinical and Economic Aspects of Osteoporosis and Osteoarthritis (ESCEO) algorithm for the management of knee osteoarthritis-From evidence-based medicine to the real-life setting. Semin Arthritis Rheum. 2016;45(4 Suppl):S3-S11. doi:10.1016/j. semarthrit.2015.11.010

\section{Publish your work in this journal}

Therapeutics and Clinical Risk Management is an international, peerreviewed journal of clinical therapeutics and risk management, focusing on concise rapid reporting of clinical studies in all therapeutic areas, outcomes, safety, and programs for the effective, safe, and sustained use of medicines. This journal is indexed on PubMed Central, CAS,
EMBase, Scopus and the Elsevier Bibliographic databases. The manuscript management system is completely online and includes a very quick and fair peer-review system, which is all easy to use. Visit http://www.dovepress.com/testimonials.php to read real quotes from published authors. 